Article

\title{
Origins and Spatial Distribution of Non-Pure Sulfate Particles (NSPs) in the Stratosphere Detected by the Balloon-Borne Light Optical Aerosols Counter (LOAC)
}

\author{
Jean-Baptiste Renard ${ }^{1, *}$, Gwenaël Berthet ${ }^{1}\left(\mathbb{D}\right.$, Anny-Chantal Levasseur-Regourd ${ }^{2}$, \\ Sergey Beresnev ${ }^{3} \mathbb{D}^{-}$, Alain Miffre ${ }^{4}{ }^{-}$, Patrick Rairoux ${ }^{4}\left(\mathbb{D}\right.$, Damien Vignelles ${ }^{1,5}$ and \\ Fabrice Jégou 1 (1) \\ 1 LPC2E-CNRS-CNES, F-45071 Orléans, France; gwenael.berthet@cnrs-orleans.fr (G.B.); \\ dvignelles@meteomodem.com (D.V.); fabrice.jegou@cnrs-orleans.fr (F.J.) \\ 2 LATMOS-CNRS-CNES, Campus Pierre et Marie Curie, Sorbonne Université, F-75252 Paris, France; \\ anny-chantal.levasseur-regourd@latmos.ipsl.fr \\ 3 Institute of Natural Sciences and Mathematics, Ural Federal University, 620083 Ekaterinburg, Russia; \\ sergey.beresnev@urfu.ru \\ 4 Institut Lumière Matière, University Claude Bernard Lyon 1, CNRS, F-69622 Villeurbanne, France; \\ alain.miffre@univ-lyon1.fr (A.M.); patrick.rairoux@univ-lyon1.fr (P.R.) \\ 5 MeteoModem Company, F-77760 Ury, France \\ * Correspondence: jean-baptiste.renard@cnrs-orleans.fr
}

Received: 31 July 2020; Accepted: 18 September 2020; Published: 25 September 2020

check for updates

\begin{abstract}
While water and sulfuric acid droplets are the main component of stratospheric aerosols, measurements performed for about 30 years have shown that non-sulfate particles (NSPs) are also present. Such particles, released from the Earth mainly through volcanic eruptions, pollution or biomass burning, or coming from space, present a wide variety of compositions, sizes, and shapes. To better understand the origin of NSPs, we have performed measurements with the Light Optical Aerosol Counter (LOAC) during 151 flights under weather balloons in the 2013-2019 period reaching altitudes up to $35 \mathrm{~km}$. Coupled with previous counting measurements conducted over the 2004-2011 period, the LOAC measurements indicate the presence of stratospheric layers of enhanced concentrations associated with NSPs, with a bimodal vertical repartition ranging between 17 and $30 \mathrm{~km}$ altitude. Such enhancements are not correlated with permanent meteor shower events. They may be linked to dynamical and photophoretic effects lifting and sustaining particles coming from the Earth. Besides, large particles, up to several tens of $\mu \mathrm{m}$, were detected and present decreasing concentrations with increasing altitudes. All these particles can originate from Earth but also from meteoroid disintegrations and from the interplanetary dust cloud and comets.
\end{abstract}

Keywords: non-sulfate stratospheric aerosols; counting; typology; balloon

\section{Introduction}

\subsection{Non-Pure Sulfate Particles (NSPs) in the Stratosphere}

The Earth's stratospheric aerosols mainly contain liquid particles as a pure mixture of water and sulfuric acid particles (hereafter, referred to as sulfate aerosols or sulfate particles). They largely originate from natural and anthropogenic emissions of oxidized carbonyl sulfide [1,2] or are released from volcanic eruptions injecting the $\mathrm{SO}_{2}$ aerosol precursor directly into the stratosphere [3-7], with an injection altitude controlled by the volcanic eruption intensity. Aerosols released from volcanic eruptions 
of moderate amplitude (i.e., about 20 times less $\mathrm{SO}_{2}$ injected than for the Pinatubo major volcanic eruption in 1991), occurring regularly since the year 2000, modulate the sulfate aerosol concentration at the global or hemispherical scale over periods of months [8]. Nevertheless, observations of the aerosol content out of such volcanic events show that particle concentration remains presently low in the stratosphere, as compared with the post-1991 period impacted by the Pinatubo volcanic eruption. Hence, in what follows, the current stratospheric conditions are typically referred to as "background" aerosol conditions with sulfate particle concentrations expected to decrease with increasing altitude above $20 \mathrm{~km}[9]$.

Although sulfate particles are the main component of the stratospheric aerosols, at least in the lower and middle stratosphere, remote sensing and in situ measurements performed for more than 30 years have shown that materials (here, we do not consider frozen material) clearly stand out from the sulfate population in terms of composition and optical properties, with abundances depending on the altitude, latitude, and season [10-15]. Such materials, which we define here as NSPs, acronym for "non-pure sulfate particles", can be in solid form only, but can also be externally-mixed (i.e., simultaneous presence of pure solid particles and pure liquid particles) or internally-mixed (i.e., included in or coated by pure sulfate). This definition clusters the various complex properties, mainly in terms of composition, shape, and conditions of sublimation, reported in the literature. NSPs can be also in the form of semi-volatile particles, such as some secondary organic aerosols, or volatile liquid particles formed from gaseous precursors with dissolved material. They can contain refractory or non-refractory material in the form of amorphous, compact, aggregated, or fractal solid parts, such as black carbon, thereafter BC, or soot particles (black carbon refers to pure carbon particles, while soot refers to carbonaceous particles including carbon and other materials). These particles are mostly optically absorbing as opposed to pure sulfate particles, which are basically transparent.

NSPs can have different origins, coming either from the Earth or from space. As detailed below, the strong variability in the corresponding measured concentration and chemical composition could be due to the various sources, including (possible) very localized contributions. The expected low concentrations of these particles, the wide variety of their shapes, their chemical compositions, and the various sensitivity of the measurement techniques have not, up to now, made it possible to reach a comprehensive vision of non-sulfate materials in the stratosphere, in terms of origins, content, physical properties, composition, and seasonal/inter-annual variability, which would be necessary to address different questions, such as radiative effects. Table 1 summarizes the main characteristics of such particles from the present knowledge.

NSPs in the stratosphere are complex subjects for study. NSPs have been detected using different remote-sensing and in situ instruments, from the ground, onboard airplanes, under balloons, and onboard satellites. None of these instruments can solely characterize these particles at all possible scales from the detection of specific events to the observation of the spatial and temporal variability of their concentrations, size distributions, and chemical composition. Then, all of these measurements must be combined to tentatively propose a comprehensive view of NSPs in the stratosphere.

The aim of this paper is to contribute to a better understanding of NSPs origins and variability in the stratosphere. We do not consider here the Polar Stratospheric Cloud particles and the liquid particles formed by condensation. For that purpose, we have developed a new strategy of measurements using the Light Optical Aerosols Counter (LOAC) by performing 151 flights under weather balloons over the mid-2013-end of 2019 period. We summarize in the next subsection the methodologies already used for the NSPs detection from ground-based up to satellite instruments. Then, we present the LOAC instrument and the results obtained for concentrations, size distribution, and temporal and spatial variabilities. Finally, we discuss the possible origins of such variabilities and the contribution of LOAC to better estimate the source of the NSPs. 
Table 1. Summary of the Various Sources of Non-Sulfate Particles (NSPs).

\begin{tabular}{ccccc}
\hline Nature & Typical Size & Source & Origin & Typical Composition \\
\hline Volcanic ashes & $<1 \mu \mathrm{m}$ & From ground & Natural & Silicates, basaltic, salts \\
\hline Biomass burning & $<1 \mu \mathrm{m}$ & From ground & $\begin{array}{c}\text { Natural and } \\
\text { anthropogenic }\end{array}$ & Carbonaceous \\
\hline Pollution & $<1 \mu \mathrm{m}$ & From ground & Anthropogenic & $\begin{array}{c}\text { Carbonaceous, } \\
\text { minerals, sulfur }\end{array}$ \\
\hline $\begin{array}{c}\text { Polymeric } \\
\text { nanocomposites }\end{array}$ & $>1 \mu \mathrm{m}$ & $\begin{array}{c}\text { Produced in the } \\
\text { atmosphere }\end{array}$ & Natural & Carbonaceous \\
\hline $\begin{array}{c}\text { Rocket exhaust } \\
\text { plume }\end{array}$ & $<5 \mu \mathrm{m}$ & $\begin{array}{c}\text { Produced in the } \\
\text { atmosphere }\end{array}$ & Anthropogenic & Alumina \\
\hline $\begin{array}{c}\text { Airplane soot } \\
\begin{array}{c}\text { Meteoroid } \\
\text { disintegration }\end{array}\end{array}$ & All sizes & $\begin{array}{c}\text { Produced in the } \\
\text { atmosphere }\end{array}$ & Anthropogenic & Carbonaceous \\
\hline $\begin{array}{c}\text { Satellite } \\
\text { produced in the } \\
\text { atmosphere }\end{array}$ & All sizes & $\begin{array}{c}\text { From space and } \\
\text { produced in the } \\
\text { atmosphere }\end{array}$ & Anthropogenic & Carbonaceous, metals, \\
silicates
\end{tabular}

\subsection{Methodologies for NSPs Detection in the Stratosphere}

Ground-based observations provide sparse or continuous measurements from a given place, meaning that events of stratospheric aerosol enhancements with or without NSPs can be detected. Remote-sensing photometric measurements at twilight have provided vertical profiles of twilight intensity that reflect the aerosol abundance. However, such measurements have been seldom conducted, mainly during meteor shower episodes, showing strong and transient aerosol enhancements in the middle and upper stratosphere [16,17].

Other transient episodes have been reported from lidar measurements in relation with a meteoroid disintegration [18], the debris of rockets or satellites [19], or wildfire plume events [20-23]. Most of these measurements are performed in the framework of the Network for the Detection of Atmospheric Composition Change (NDACC) or European Aerosol Research Lidar Network (EARLINET). However, there is no direct determination of the precise size distribution and concentration of the particles, although indications on the altitude dependency of their nature (liquid, solid, mixed) and their mean size values can be derived from the depolarization they induce on the backscattered laser light [24]. Such analyses are conducted from an optical point of view by partitioning the stratospheric aerosol into icy particles and spherical particles containing sulfate component, whose contribution to light backscattering is well-known, and non-sulfate optical components, which mainly refers to light-absorbing material, including BC and soot. In particular, such a partitioning was already performed [25] in the troposphere when coupling incandescence and lidar field measurements.

Airplanes can perform long horizontal excursions, as well as shorter vertical profile excursions in the lower stratosphere, up to about $22 \mathrm{~km}$ altitude, by carrying instruments for in situ measurements during dedicated field campaigns. The main difficulty could be the collection of very large particles greater than several tens of $\mu \mathrm{m}$, although specific collecting methods have been developed to limit the possible breaking of the particles due to relative speeds of up to $200 \mathrm{~m} / \mathrm{s}$ [26].

Historically, the first campaigns were conducted to collect interplanetary dust with subsequent laboratory analysis by electronic microscopy (TEM/SEM) and energy-dispersive X-ray microanalysis $[27,28]$. National Aeronautics and Space Administration (NASA) has been collecting dust in the stratosphere since the beginning of 1981 with the so-called U-2, ER-2, and WB-57 airplanes. These flights have mostly ranged over most of the USA (as far as north as Alaska) and Central America. The main challenging tasks are to distinguish between the refractory material coming either from space 
or from the Earth, and to determine the natural or anthropogenic origin of these particles through morphology and composition analyzes [29-32].

In situ optical counting instruments onboard airplanes provide the size distribution of the particles greater than about $0.2 \mu \mathrm{m}$ in the lower stratosphere. Conventional counters are highly sensitive to the complex refractive index of the particles [33,34]; BC particles can typically be up to 10 times darker than liquid sulfuric-acid aerosols of the same size. To accurately retrieve the size distribution, the nature of the detected aerosols must be known when processing the data, otherwise the contribution of the optically absorbing particles could be strongly underestimated. A more complete methodology consists in evaluating the total aerosol concentration and that of non-volatile materials from two different collecting channel (the latest being heated to $250^{\circ} \mathrm{C}$ ). The fraction of stratospheric particles, which are not entirely composed of volatile material (mainly water and sulfuric acid), is then evaluated by calculating the difference between these two channels [11].

The in situ scattering and incandescence techniques, where the aerosols are also heated, can be used to determine the size distribution of the submicron particles down to $0.2 \mu \mathrm{m}$, the proportion of light-absorbing refractory NSPs, the determination of bulk composition (such a BC), and information about the possible presence of coating $[10,35,36]$.

Finally, the in situ mass spectrometry provides the composition of the particles and the vertical profile of the partitioning between various families of NSPs containing (or not) carbonaceous material and metals [37-39]. However, from this technique, it is difficult to conclude whether the metallic elements are dissolved or are in the form of refractory inclusions in the sulfate particles.

Stratospheric (zero pressure) balloons can reach $40 \mathrm{~km}$ altitude and stay up to a few tens of hours in flight. They are well-adapted to study the middle stratosphere above altitudes reached by airplanes. Measurements can be conducted during ascent, at float, and during a slow descent. However, technical and operational constraints strongly restrain the number of flights and the geographic zones for launches.

Remote sensing measurements using natural light sources (Sun, Moon, stars) can provide the vertical profile of aerosols extinction with a resolution of a few hundreds of meters, generally in the UV-visible domain [40]. For liquid aerosols, the size distribution can be retrieved using Mie scattering calculations. Such an observational method needs to assume that the stratosphere is composed of horizontally homogeneous layers along lines of sight of tens to hundreds of $\mathrm{km}$ long, although significant local concentration variations can bias the retrieval [41]. Nevertheless, non-monotonic UV-visible extinctions could be an indicator of the possible presence of optically absorbing material in the stratosphere together with the sulfate aerosol population [40-42]. Moreover, the measurements of the local radiance scattering function for the aerosols [43] can be used to distinguish between sulfate and other types of particles [13]. However, such studies have not addressed the possibility for the aerosols to be internally or externally mixed.

The optical aerosol counters are easier to use from balloons than from airplanes, since the relative speed between the instrument and the ambient air is low, around $5 \mathrm{~m} / \mathrm{s}$ during ascent or slow descent, and close to zero at float. They can typically detect particles with sizes from about $0.2 \mu \mathrm{m}$ to a few $\mu \mathrm{m}[9,33]$, and provide the vertical profiles of the aerosols for several size classes. An improved optical particle counter has been used to detect the fraction of aerosols that are charged probably by the galactic cosmic rays [44]. Such charged particles could have some implication in the high-energy phenomena in the middle and upper atmosphere [45].

The negligible speed between the balloon and the ambient air at float altitude is optimal to collect the particles without breaking them. As for airplane collection, the particles are analyzed in the laboratory after a soft landing of the gondola [46-48].

Finally, satellite instruments can provide a global coverage of the aerosol content in the stratosphere [8,49-52]. They can be used to derive trends over several years or to study locally strong sources of aerosols. For such remote sensing measurements, inversion methods are necessary to retrieve the vertical profiles using assumptions on the complex refractive index of the particles 
and/or on the shape of the size distribution [53]. The local variability of the aerosol content can be potentially diluted along the line of sight and/or could be removed when applying smoothing or filtering procedures; nevertheless, it is possible to follow intense events of injection of refractory material in the stratosphere from fires (carbonaceous particles), volcanoes (ash), and meteoroid disintegrations [54-58]. Moreover, extinction measurements can be used to search for the presence of NSPs with respect to the pure sulfate population in the middle stratosphere [59].

The space-borne lidar measurements, such as the Cloud-Aerosol Lidar with Orthogonal Polarization (CALIOP) instrument onboard the Calipso satellite (https://www-calipso.larc.nasa.gov/), are mainly dedicated to the detection of clouds and aerosols in the boundary layer [60], since the scattered signal is often too low for the detection of stratospheric aerosols. Moreover, reference altitudes used to derive the Rayleigh signature in the lidar retrieval, and assumed to be aerosol-free, are often too low to detect stratospheric aerosols above $30 \mathrm{~km}$ [61]. Nevertheless, analyses can be conducted during specific events of carbonaceous particles or of gaseous precursors driven by the pyro-convection, or by the Asian monsoon [21,62-64].

Finally, attempts to collect dust from space entering the Earth's atmosphere were made from Gemini 10, Skylab, Salyut 7, and Mir space stations, and from the retrieval of space exposed surfaces of satellites. The Long Duration Exposure Facility (LDEF) was exposed for almost 6 years at altitudes ranging from 580 to $332 \mathrm{~km}$, and provided evidence for cosmic dust particles [65-67] that do enter the Earth's atmosphere.

\section{Present Approach with Balloon-Borne Aerosol Counters}

\subsection{Context}

The previous measurements reported above have shown that the stratospheric content of NSPs could exhibit a strong horizontal, vertical, and temporal variability, since the sources of NSPs can be diverse. Regular and frequent in situ measurements are of high relevance to derive the stratospheric aerosols content and to follow its evolution. The a priori assumptions on the shape, the composition, and the size distribution of the particles commonly used in data retrievals from remote sensing instruments $[53,68]$ are then minimized.

The University of Wyoming aerosols counters $[4,9,69]$ and the Stratospheric and Tropospheric Aerosols Counter (STAC) [13,70] have provided, locally, the size distribution and the concentrations of aerosols up to $40 \mathrm{~km}$ in altitude when launched under (large) stratospheric balloons. In particular, during its 21 flights over the 2004-2011 period, STAC has recurrently detected strong aerosol concentration enhancements over a vertical extent from a few hundreds of meters to a few kilometers.

Such instruments were calibrated for the detection of liquid particles typically in the $0.2-5 \mu \mathrm{m}$ size range. Since their measurement technique is sensitive to the complex refractive index of the particles, these instruments cannot be used to distinguish between transparent liquid particles and optically absorbing NSPs, the size of the latest being possibly underestimated. The weight of the instrument is of several $\mathrm{kg}$, preventing them to be used under small balloons as weather balloons.

Given that the aerosol content does not necessarily vary homogeneously throughout the stratosphere, especially under the influence of sporadic events (volcanic eruptions, fires, meteoroid disintegrations), regular and frequent in situ measurements must be conducted from several locations around the world. Accounting for operational constraints and cost issues, it seems that the most valuable method is to launch light and inexpensive instruments under weather balloons, sending the data by a telemetry system, with the risk of losing the instrument after the flight. Such types of balloons can reach an altitude of $35 \mathrm{~km}$, but the burst of the balloon cannot be controlled. The payload weight must be below a few $\mathrm{kg}$ to account for the international aeronautic rules. The costs for the balloons and the gas are no more than a few hundreds of euros. Two or three people are necessary to launch the balloon from almost everywhere. The wind speed at ground could be up to $15 \mathrm{~m} / \mathrm{s}$. Then, frequent 
measurements, typically tens of flights per year, can be conducted regularly and during specific events almost from everywhere.

Light instruments are not currently available for collecting samples for return or for mass-spectrometry. However, two light optical aerosols counters with a weight of about $1 \mathrm{~kg}$ are now available on the market. The first one is the Printed Optical Particle Spectrometer (POPS), designed for the detection of liquid particles in the $\sim 0.15-1 \mu \mathrm{m}$ size range [71]. It can provide very accurate size distributions and concentrations of submicron sulfate stratospheric aerosols with a vertical resolution of $100 \mathrm{~m}$ or better, but is not designed to detect the largest particles previously detected in the stratosphere $[47,72]$, and cannot identify the optically absorbing particles. The second one is the Light Optical Aerosols Counter (LOAC). LOAC is a novel instrumental concept [73] providing the size distributions, the concentrations, and an estimate of the typology, for particles in the $0.2-50 \mu \mathrm{m}$ size range. As detailed in the next subsection, LOAC is primarily not sensitive to the complex refractive index of the particles; it can, thus, detect particles of different compositions including very optically absorbing ones. LOAC is especially appropriated for the detection of the NSPs, as previously shown for dust particles in the troposphere [74], while the POPS is better designed for the detection of the submicron sulfate aerosols; then, these two instruments can be considered as complementary.

\subsection{The LOAC Instrument}

The particles are injected across an optical chamber by a pumping system, cross a laser beam, and the light scattered by the particles is recorded by two detectors. Conventional aerosols counters typically performed measurements at large scattering angles (greater than $30^{\circ}$ and often around $\left.90^{\circ}\right)$. Since the scattered light at these angles is sensitive to the size of the particles, but also to their complex refractive index and their shape, including porosity effects [75]; conventional optical counter measurements must be corrected for the nature of the particles.

In contrast, LOAC performs counting and sizing measurements at small scattering angles, in the $11^{\circ}-16^{\circ}$ range, where the scattered light by irregular particles is mainly coming from diffraction that does not depend on the complex refractive index, nor on the porosity of the irregular-shaped particles [73,76]. As a result, a direct correspondence between the intensity of the scattered light and the optical diameter of the particles becomes feasible. LOAC provides particles number concentrations for 19 sizes in the $0.2-50 \mu \mathrm{m}$ size range, with an uncertainty of $\pm 20 \%$ for concentrations higher than 10 particles $\mathrm{cm}^{-3}$. Following the Poisson statistics, the uncertainty increases to about $\pm 30 \%$ for submicron particle concentrations higher than 1 particle $\mathrm{cm}^{-3}$, and to about $\pm 60 \%$ for concentrations smaller than $10^{-2}$ particle $\mathrm{cm}^{-3}$. The particle size provided by LOAC is an optical diameter, which could differ from aerodynamical, electric mobility, and gyration diameters used by other counting techniques in case of irregular (and possibly porous) particles. Moreover, the refractory particles could be hydrated, thus, having a size greater than dried particles. The uncertainties in the size determination is of $\pm 0.025 \mu \mathrm{m}$ for particles smaller than $0.6 \mu \mathrm{m}, 5 \%$ for particles in the $0.7-2 \mu \mathrm{m}$ range, and of $10 \%$ for particles greater than $2 \mu \mathrm{m}$. LOAC uses a statistical approach to retrieve the concentration of particles smaller than $1 \mu \mathrm{m}$. When the concentration of submicron particles is low, typically below 10 particles $\mathrm{cm}^{-3}$ for sizes greater than $0.2 \mu \mathrm{m}$, the integration time must be increased up to $10 \mathrm{~min}$. Thus, when used under balloon, the vertical resolution of LOAC is between $1 \mathrm{~km}$ and $3 \mathrm{~km}$ for an ascent speed of about $5 \mathrm{~m} / \mathrm{s}$.

The ability of LOAC to accurately detect micron-sized particles and larger particles has been validated during numerous intercomparison sessions with different instruments $[74,75]$. The raw LOAC concentrations must be corrected for the sampling efficiency when the measurements are conducted under balloon, the sampling being dominated by sub-isokinetic conditions and the divergence of the flow field at the inlet entrance.

LOAC has a second detector at a scattering angle in the $50^{\circ}-70^{\circ}$ range. Counting measurements are also performed at this angle, where the scattered light is sensitive to the complex refractive index and to the porosity of the particles. By statistically combining these measurements with those at $11^{\circ}-16^{\circ}$, we obtain a parameter called "speciation index", which is representative of the properties of 
the particles to absorb light [73]. The higher the speciation index, the darker the particles. Speciation index reference measurements were conducted in a laboratory with pure reference samples to establish a database. By comparing the ambient air measurements to the database, we can tentatively identify the basic nature of the particles, or typology. As confirmed during tests in the laboratory and in ambient air, LOAC can indicate if the detected aerosols are icy, are in a non-optically absorbing liquid phase as the typical stratospheric pure sulfate population, are semi-transparent NSPs as some dry minerals or highly hydrated solid aerosols, or are optically-absorbing NSPs as carbonaceous particles. It is not possible to know if the particles are externally or internally mixed with sulfate or can be considered as a secondary organic aerosol. This approach is a first step to validate the ability of optical measurements to provide an estimate of the nature of the stratospheric aerosols.

LOAC can be used frequently to perform measurements in the stratosphere to evaluate the vertical and temporal variability of the aerosol content, to identify the presence of NSPs, and to better determine the concentration of large particles greater than $5 \mu \mathrm{m}$ and up to $50 \mu \mathrm{m}$.

\subsection{Vertical Profile of Aerosol Concentrations Obtained with LOAC}

The LOAC gondola includes batteries, telemetry to send the data in real time, and temperature and humidity sensors, using the Meteomodem Company system [77]. From May 2013 to the end of 2019, 151 balloon flights reaching the stratosphere have been successfully conducted from France, from Spain, and from Ile de la Réunion (Indian Ocean). The balloons are called "Light Expandable Balloons" since they carry a scientific instrument that can be recovered (in case of landing on the ground), to distinguish them for conventional weather balloons. The duration of the flight is of about $2 \mathrm{~h}$. Regular flights, from one to four per month, have been operated since February 2014 from France, mainly by Centre National d'Etudes Spatiales (CNES), the French Space Agency, from its balloons launching base at Aire sur $\mathrm{l}^{\prime}$ Adour $\left(43.70^{\circ} \mathrm{N}, 0.25^{\circ} \mathrm{W}\right)$. Figure 1 illustrates a LOAC launch from Aire sur l'Adour on 6 February 2014.

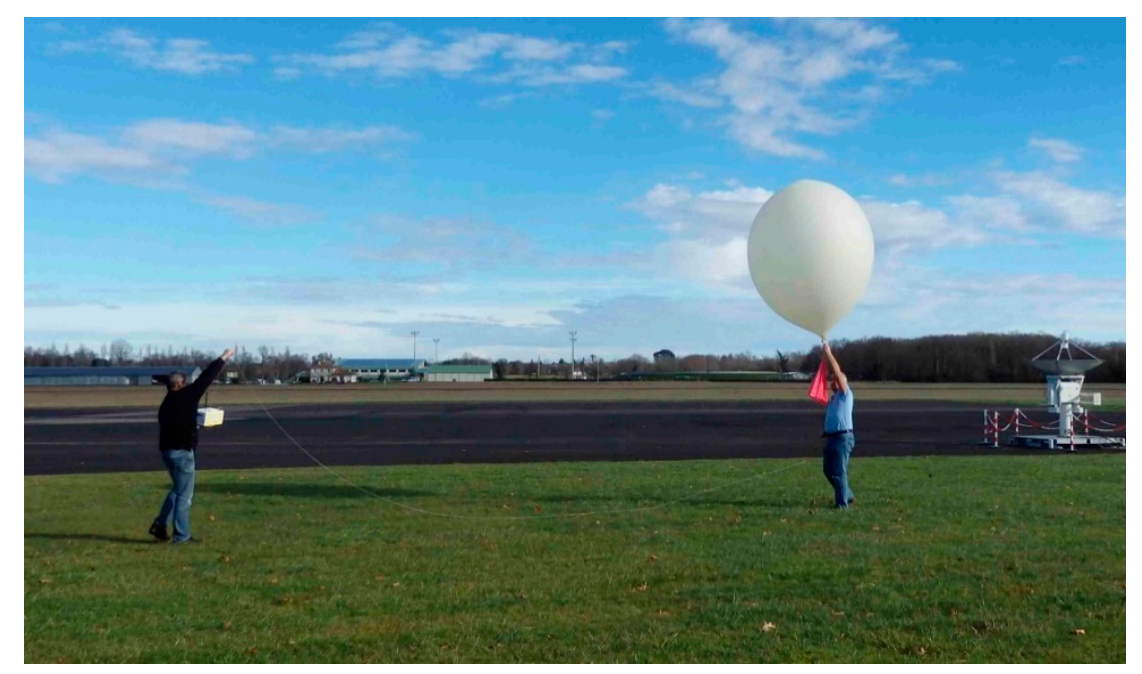

Figure 1. Light Optical Aerosol Counter (LOAC) launch from Aire sur l'Adour (France; $43.70^{\circ} \mathrm{N}, 0.25^{\circ}$ W) on 6 February 2014.

The mean evolution with altitude of concentrations of particles greater than $0.2 \mu \mathrm{m}$ can be estimated considering all LOAC flights. At each $\mathrm{km}$, the histogram of the concentrations is calculated and is fitted in log scale with a lognormal function to estimate the mode corresponding to the most frequent concentration. As expected for background stratospheric aerosols, the vertical profile of this mode, in red in Figure 2, decreases with increasing altitudes. The individual profiles fluctuate on both sides of the mode profile, probably due to the local variability of the aerosol content. Nevertheless, the variability is higher for the greatest concentrations, with several strong increases of km-width. Such 
kind of increases reflects those previously reported [70] in the middle stratosphere using the STAC balloon-borne aerosol counter.

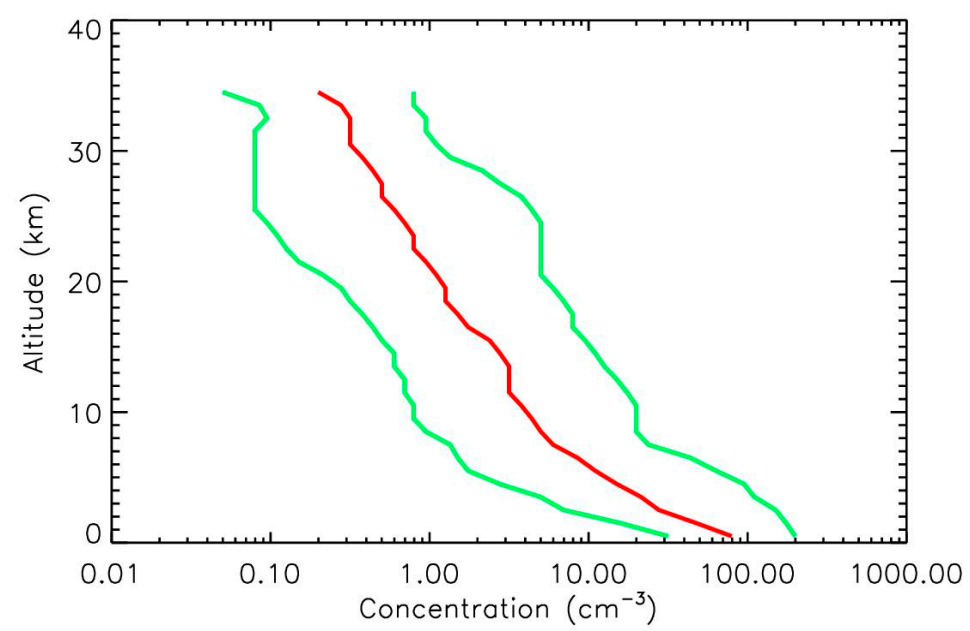

Figure 2. Vertical evolution of the number concentrations of particles greater than $0.2 \mu \mathrm{m}$ considering all LOAC flights; the red line corresponds to the mode of the most frequent concentrations and the green lines corresponds to the first and third quartiles.

Examples of individual profiles are presented below, to illustrate the variability of the stratospheric aerosol content. Figure 3 presents an example of vertical evolution of the particle number concentrations for a LOAC flight on 17 August 2017, from Aire sur l'Adour in case of background conditions. Globally, the aerosol concentrations decrease with altitude from the ground to the middle stratosphere. More precisely, after a small enhancement in the lower stratosphere (Junge layer), the aerosol concentrations decrease with altitude above $20 \mathrm{~km}$ as expected for sulfate aerosols. In Figure 4, the retrieved typologies in the stratosphere (small diamonds compared to the "typology zones" drawn from the speciation index data base obtained in the laboratory) indicate that the submicron aerosols are indeed transparent liquid droplets based. Note that in this example, the number of detected particles for size classes above $3 \mu \mathrm{m}$ is too low for the typology determination.

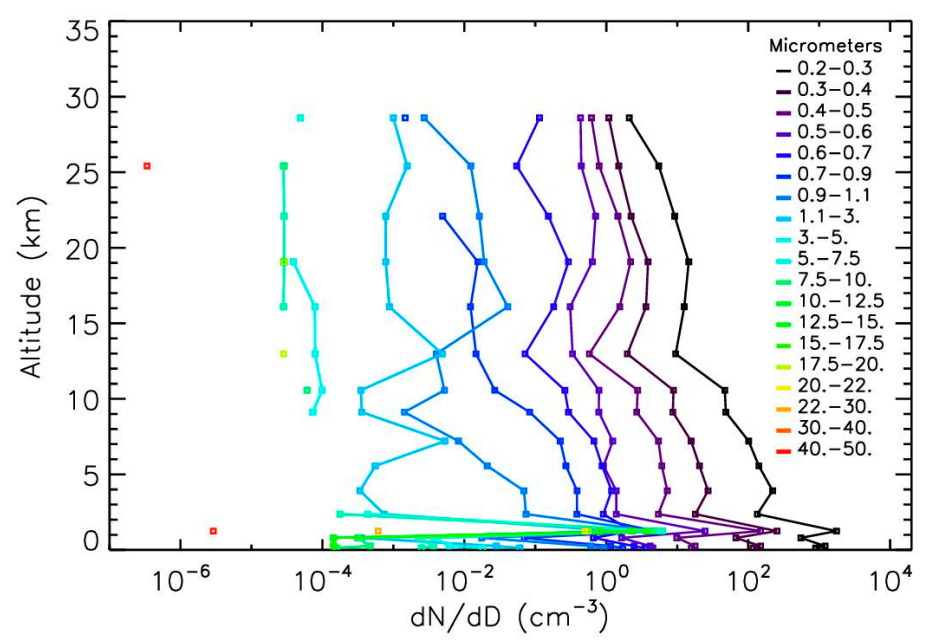

Figure 3. Vertical profile for the LOAC flight on 17 August 2017, from Aire sur 1'Adour (France; $43.70^{\circ} \mathrm{N}, 0.25^{\circ} \mathrm{W}$ ) during the Perseids meteor shower period. Errors bars (see text) are omitted for clarity reasons. 


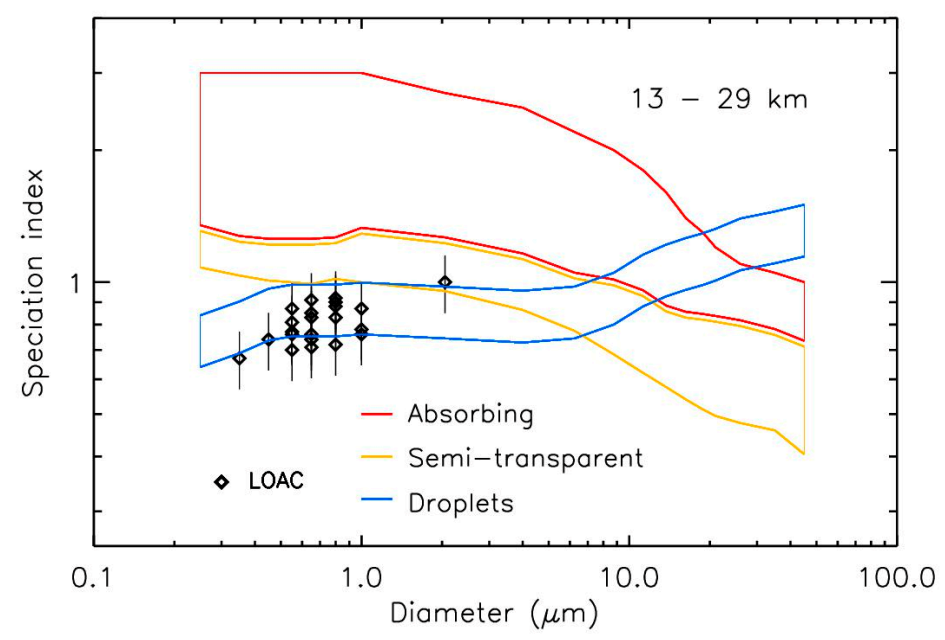

Figure 4. Indications of typology from the LOAC speciation index in the stratosphere for the 17 August 2017, flight.

Few particles greater than $5 \mu \mathrm{m}$ are detected above the tropopause, and one particle larger than $40 \mu \mathrm{m}$ is present at $25 \mathrm{~km}$ altitude (such big particles are so luminous when crossing the LOAC laser beam that they can be easily detected even if their number concentration is very low). Since the flight was conducted while the several-days duration annual Perseids meteor shower took place, one could suggest that LOAC has detected some dust particles coming from space (interplanetary dust or meteoritic material), although terrestrial sources are also possible, as proposed in part 2.4. Moreover, a contamination effect by the balloon above the instrument cannot be totally excluded.

LOAC has detected some significant vertical variability of aerosol concentrations from one flight to another, but also during a same flight, although measurements were conducted in expected volcanically quiescent conditions. During the same flight, we consider that a strong concentration enhancement is detected when the concentrations are at least 5 times higher than concentrations above and below the enhancement for at least 3 consecutive size classes of particles (this criterion is to ensure that the enhancements are real and are not due to noise measurement fluctuations). We exclude the measurements conducted at the edge of the polar vortex where the local dynamical variability can affect the aerosols content [13].

Figure 5 presents an example of a strong concentration enhancement in the lower stratosphere at an altitude of $18 \mathrm{~km}$ as observed during a flight conducted from Aire sur l'Adour on 11 August 2016, during the Perseids meteor shower period (the large particles between 8 and $12 \mathrm{~km}$ altitude correspond to a cirrus cloud). The size distribution at $18 \mathrm{~km}$ differs from those below and above the enhancement with several particles bigger than $5 \mu \mathrm{m}$ detected at this altitude (Figure 6). The typology (Figure 7) indicates that particles up to $2 \mu \mathrm{m}$ are indeed in liquid phase, in this case certainly sulfates, whereas biggest ones are classified as strongly optically absorbing NSPs. It is an open question whether these optically absorbing particles are linked to the long-duration annual (and thus moderate) Perseids meteor shower or not. 


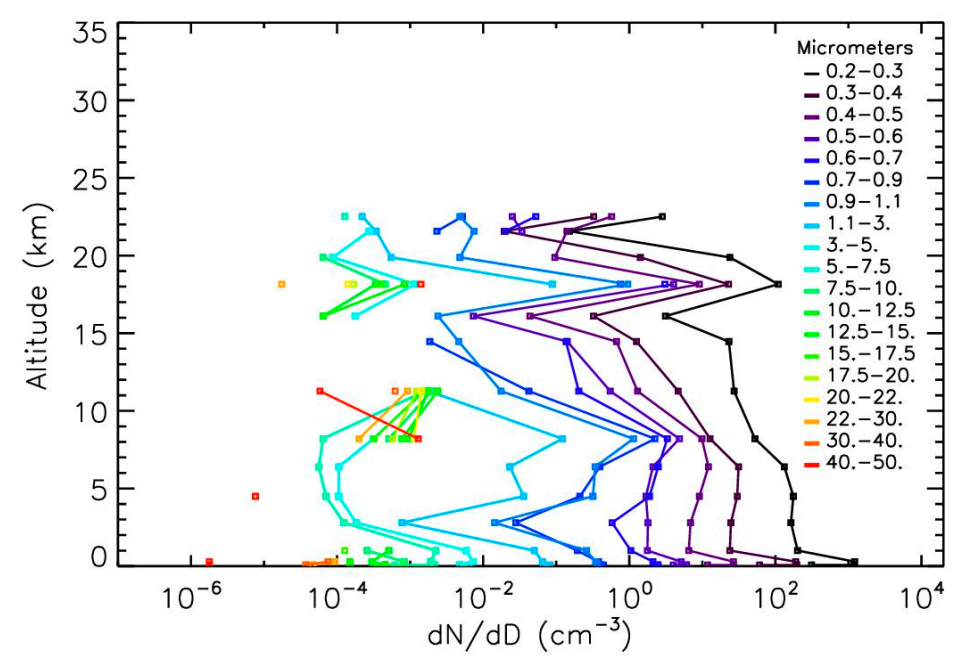

Figure 5. Vertical profile for the LOAC flight on 11 August 2016, from Aire sur l'Adour (France; $43.70^{\circ} \mathrm{N}, 0.25^{\circ} \mathrm{W}$ ) during the Perseids meteor shower period. Errors bars (see text) are omitted for clarity reasons.

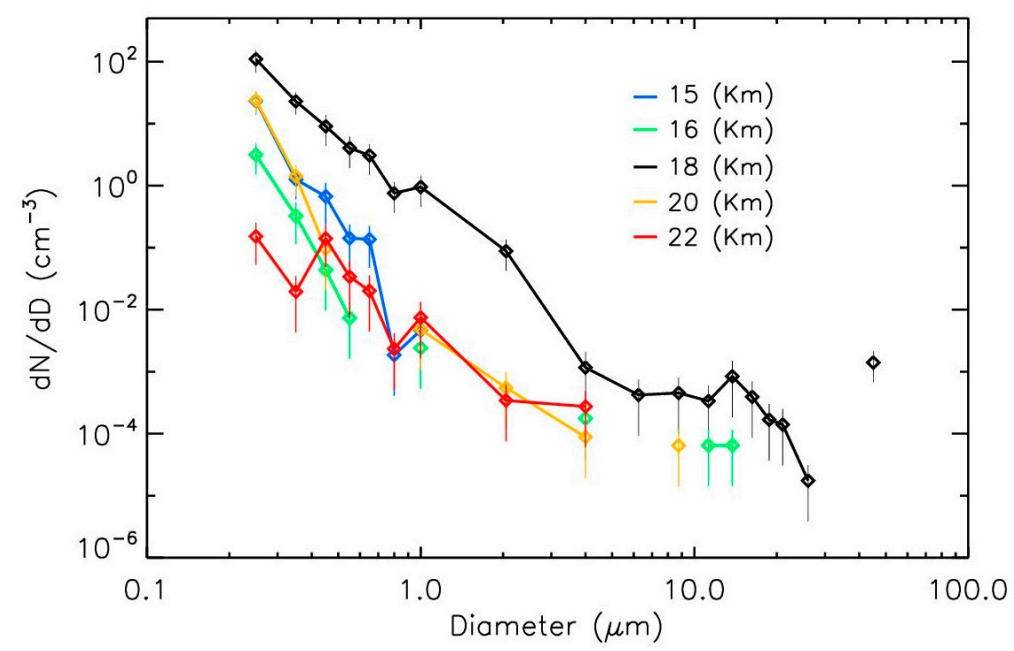

Figure 6. Evolution of concentrations with particles size for different altitudes around the concentration enhancement at $18 \mathrm{~km}$ for the 11 August 2016, flight.

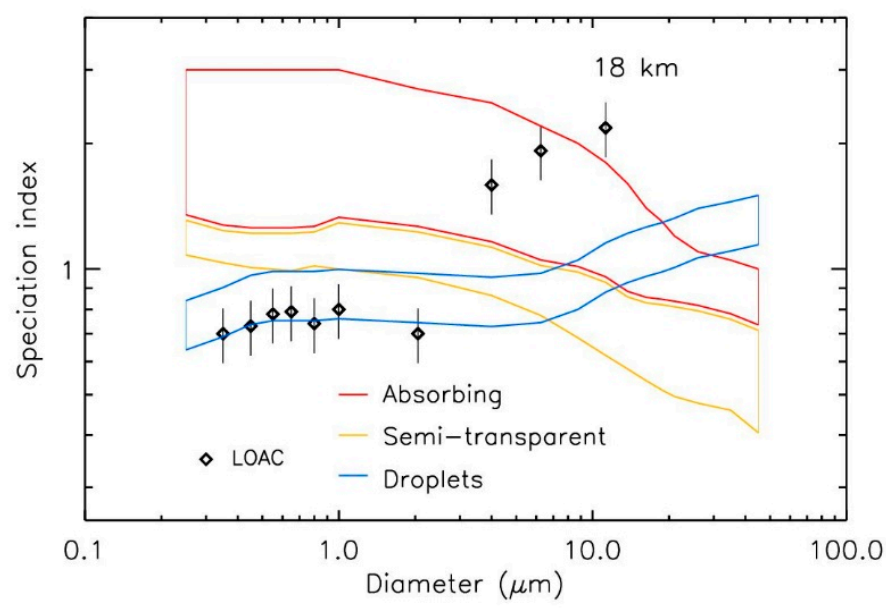

Figure 7. Indications of typologies from the LOAC speciation index in the stratosphere for the 11 August 2016, flight. 
Figure 8 presents another example of concentration enhancement observed in the middle stratosphere at an altitude of 28-29 km during a flight on 23 November, 2017, from Aire sur l'Adour. This time, the enhancement deals only with submicron particles (Figure 9). The typology indications (Figure 10) cannot be easily interpreted; one explanation could be the presence of a mixture of liquid and solid optically absorbing particles, having a composition evolving with size.

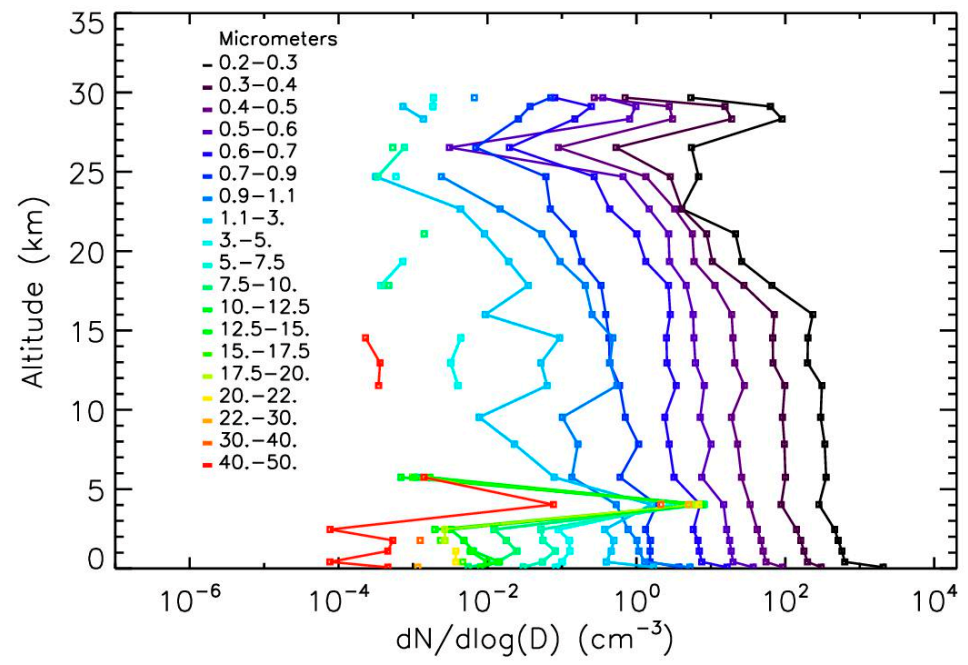

Figure 8. Vertical profile for the LOAC flight on 23 November, 2017, from Aire sur l'Adour (France; $43.70^{\circ} \mathrm{N}, 0.25^{\circ} \mathrm{W}$ ). Errors bars (see text) are omitted for clarity reasons.

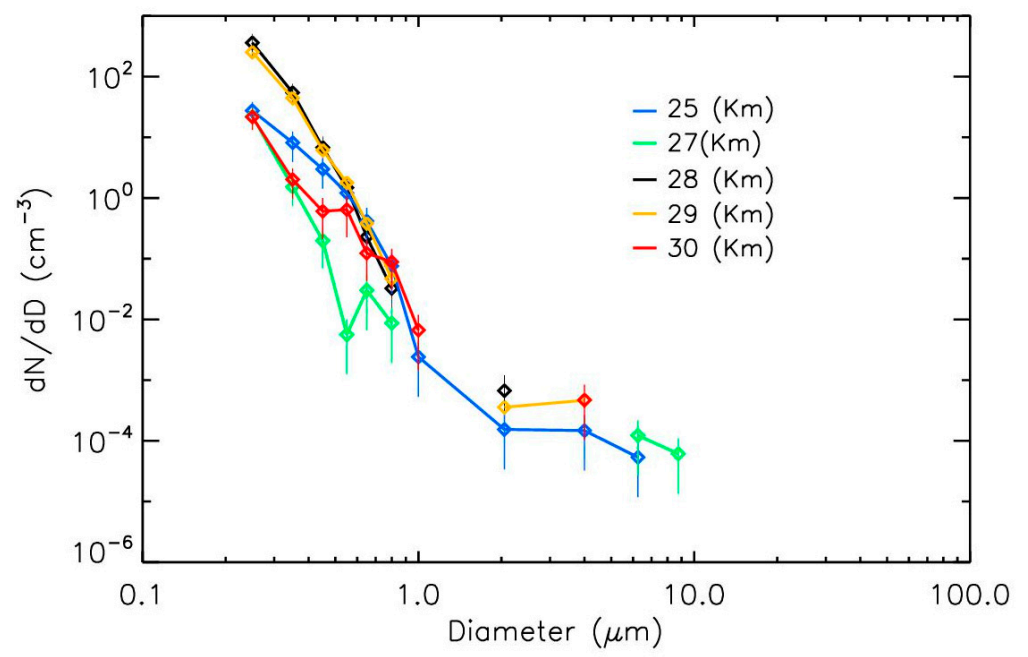

Figure 9. Evolution of concentrations with particles size for different altitudes around the concentration enhancement at $18 \mathrm{~km}$ for the 23 November, 2017, flight. 


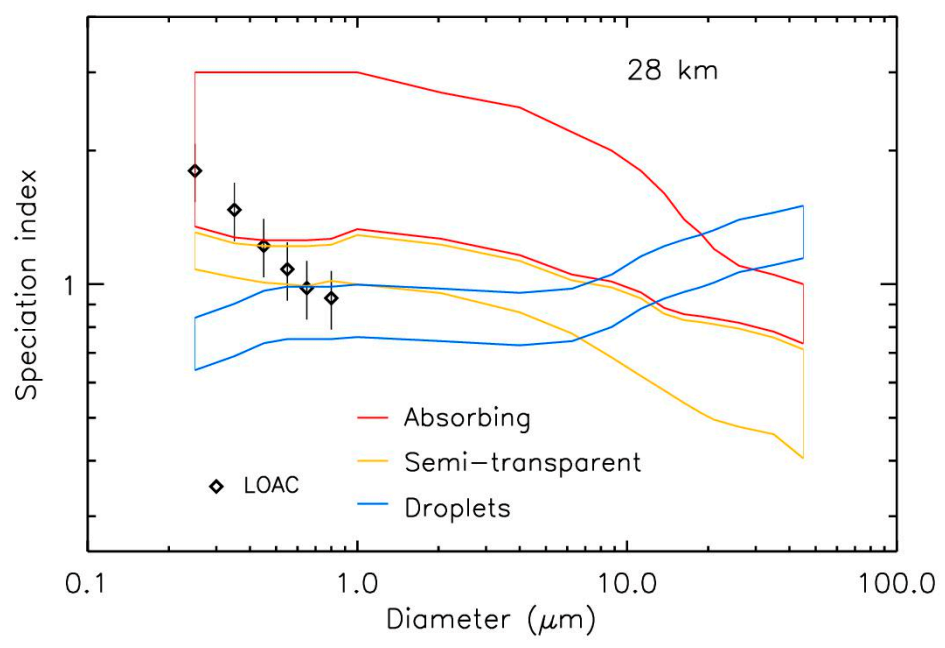

Figure 10. Indications of typologies from the LOAC speciation index in the stratosphere for the 23 November 2017 flight.

These two examples illustrate the two categories of concentration enhancements detected by LOAC. The first category reflects enhanced concentrations for all size classes and the presence of large particles, and the second category concerns submicron particle enhancements only. Table 2 presents the statistics for such detections that are dominated by the presence of large particles and strong enhancements (more than 10 times above the background content). The LOAC typology measurements indicate that the enhancements are dominated by NSPs (more than 65\%). Nevertheless, the speciation index varies from one flight to another from semi-transparent to strongly optically absorbing particles, suggesting that different families of NSPs or mixtures of different particle types could have been detected.

Table 2. Statistics of the Enhancement Concentrations.

\begin{tabular}{cccccc}
\hline $\begin{array}{c}\text { Enhancement } \\
\text { Categories }\end{array}$ & $\begin{array}{c}\text { Number of } \\
\text { Events (from } \\
\text { 151 Flights) }\end{array}$ & Mainly NSPs & $\begin{array}{c}\text { Mainly } \\
\text { Sulfates }\end{array}$ & $\begin{array}{c}\text { Enhancements } \\
\text { < 10 Times the } \\
\text { Background } \\
\text { Content }\end{array}$ & $\begin{array}{c}\text { Enhancements } \\
\text { > 10 Times the } \\
\text { Background } \\
\text { Content }\end{array}$ \\
\hline $\begin{array}{c}\text { Presence of } \\
\text { particles }>2 \mu \mathrm{m} \\
\begin{array}{c}\text { Particles }<2 \mu \mathrm{m} \\
\text { only }\end{array}\end{array}$ & 30 & 20 & 10 & 10 & 20 \\
\hline
\end{tabular}

\subsection{Origin of Stratospheric Concentration Enhancements and Transport Mechanisms}

The origin of stratospheric concentration enhancements is now analyzed, considering complementary observations. Such local concentration enhancements in the middle stratosphere, at least 5 to 100 times higher than background levels, have been previously detected by the balloon-borne STAC aerosol counter, having operated from 2003 to 2011 (21 flights) at various latitudes [13,70]. Such enhancements have been mostly detected in the middle stratosphere and, as for LOAC observations, are dominated either by particles of all sizes or by the smallest particles only. About $25 \%$ of the LOAC and STAC flights exhibit such strong enhancements. Although STAC has not been designed to distinguish between liquid and optically absorbing particles in terms of sizing, particles up to $5 \mu \mathrm{m}$ were detected in some enhancements, unlikely to be pure sulfuric acid aerosols at such altitudes. In particular, eight STAC flights were conducted above northern Sweden from 2 August, to 7 September 2009, showing a strong variability from one day to another of the aerosol content and of the transient enhancements [70]. The enhancements could be very local, i.e., of a few $\mathrm{km}$ in term of horizontal extent [13]. 
These enhancements were observed sometimes during well-known annual meteor shower periods of moderate intensity [78] but also apart from these events. To search for a possible seasonality in the occurrence of the enhancements, all of the LOAC and STAC flights are binned in each week during which the measurements were performed. Then, the number of concentration enhancements detected each week is calculated and is divided by the number of flights performed during the week for normalization. The results are plotted in Figure 11, as a function of the day of the year. The main meteor showers are represented by dotted lines. It seems that no obvious correlation can be found between the variability of the number events and the meteor shower dates, although some fortuitous coincidence can exist. Only $15 \%$ of the enhancements occur in a period starting 3 days before the maximum intensity of the meteor shower and ending 7 days later. Then, it can be concluded that the concentrations enhancements in the stratosphere detected by LOAC and STAC are not related to the annual meteor showers. Nevertheless, some enhancements (not necessarily detected by LOAC and STAC) could be related to sporadic meteor showers events that could occur periodically or could be due to meteoroids disintegration.

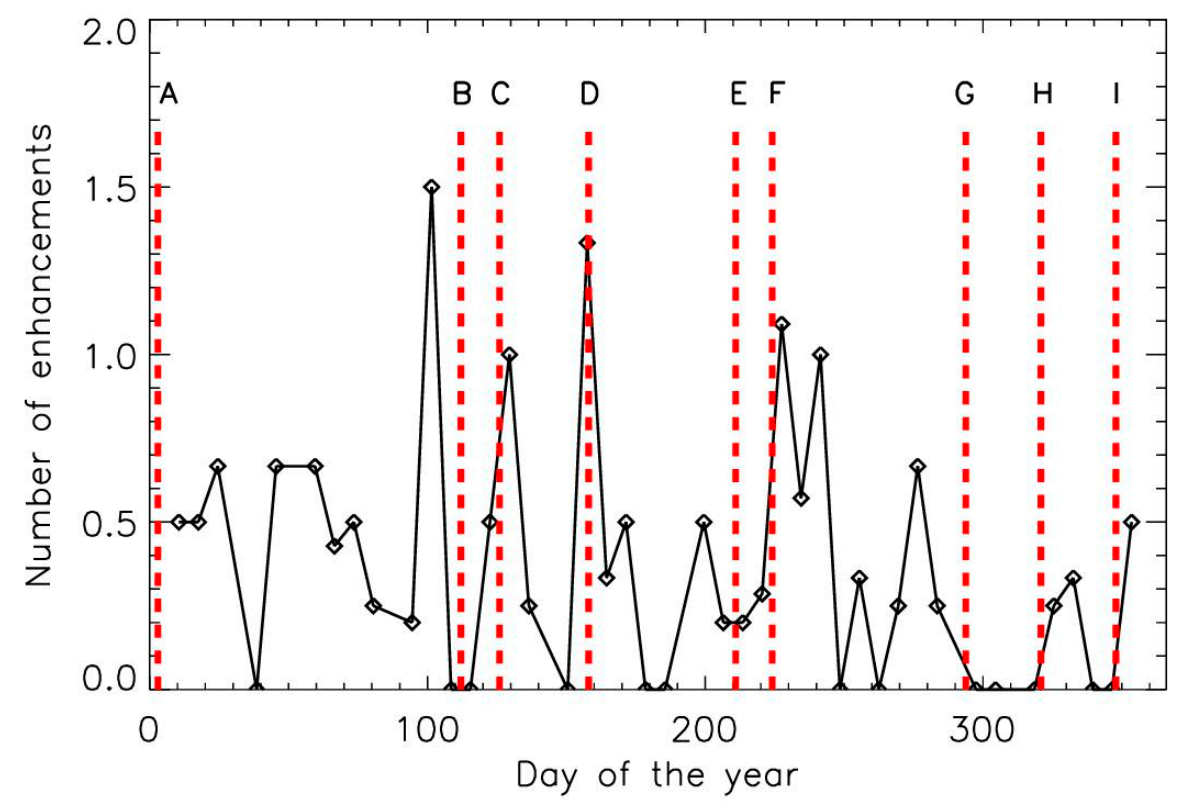

Figure 11. Number of concentration enhancements detected each week divided by the number of flights during the week, for all the LOAC and STAC measurements. The red dotted lines represent the main annual meteor showers episodes. A: Quadrantids; B: Lyrids; C: $\eta$-Aquariids; D: Arietids; E: $\delta$-Aquariids; F: Perseids; G: Orionids; H: Leonids (background conditions); I: Geminids.

On the other hand, different dynamical processes may be proposed to explain some concentration enhancements of NSPs detected by our aerosol counters and by other authors. A process diffe0ing from the common atmospheric transport mechanisms, the gravito-photophoretic effect $[79,80]$, could allow light-absorbing particles (such as BC) to be lifted until the gravity counteracts their ascent. The direction of the photophoretic force is opposite to gravity; this force can exceed the weight of the particles larger than $1 \mu \mathrm{m}$ and can be responsible for the formation of layers of optically absorbing particles between 20 and $30 \mathrm{~km}[81,82]$. Such effect could explain the transport of carbonaceous particles higher up in stratosphere, as for the 2017 Canadian wildfires [22,83], well above the altitude where the pyro-convection effect can inject the particles in the lower stratosphere. Considering these processes, such carbonaceous aerosol layers could stay in large quantities for several months during some specific events [84], but also could be present ubiquitously in the tropical lower stratosphere [12,39].

For particles of any nature, vertical winds in the stratosphere could be the basic force mechanism rather than gravito-photophoresis for the formation and the spatial and temporal stability of aerosol 
layers $[85,86]$. The vertical winds could provide a levitation of the particles in the stratosphere and could form spatial dynamical traps, in which aerosols are compelled to be in form of thin layers. The averaged vertical wind could be the strong competitor of turbulent diffusion that prevents from the stratification of stratospheric aerosols.

Another process could provide the levitation and the accumulation layers of soot and $\mathrm{BC}$ particles: the radiometric photophoresis effect. Improvements in the theoretical works show that accumulation layers of soot and BC particles could exist at different altitudes in the stratosphere depending on the size and the shape (compact or fractal) of the particles [87]. The larger the particles are, the potentially higher the accumulation layers could be. In a steady-state atmosphere, accumulation layers of submicron soot can be in the 10-30 km altitude range; soot aggregates of several micrometers could reach $60 \mathrm{~km}$ altitude. However, in a non-steady atmosphere, we may expect that these layers are dynamically perturbed and then can disappear.

Finally, strong gravity-wave events could also locally increase the aerosols content and can produce thin layers, as observed one time at mid-latitude with the balloon-borne LOAC [88].

Some of these phenomena could explain most of the concentration enhancements attributed to NSPs and previously detected by the STAC balloon-borne aerosols counter at different altitudes and locations $[13,70]$, and also for the sparse enhancements of carbonaceous particles observed by CALIOP/Calipso during the monsoonal convective season over India [63]. Soot particles can have different size distributions and fractal/compact shape depending on their origin and their aging [89], which could explain the various altitudes for the detected accumulation layers. Nevertheless, some enhanced concentrations layers could be also present after the disintegration of incoming extraterrestrial material.

A statistical analysis of the altitudes of the concentration enhancement events detected by LOAC and STAC seems to indicate a bimodal repartition, one centered at around $17 \mathrm{~km}$ and the second one centered at around $30 \mathrm{~km}$ (Figure 12). The analysis is conducted by calculating the percentage of events in respect with the total number of measurements available at a given altitude. This bimodal repartition looks like the one proposed in [87] for the accumulation layers of fractal particles that could correspond to dense aggregates (density of $2 \mathrm{~g} \mathrm{~cm}^{-3}$ ) and of fluffy aggregates (densities in the $0.16-0.35 \mathrm{~g} \mathrm{~cm}^{-3}$ ). In a steady-state atmosphere, under the action of the photophoresis, the accumulation layers could be in the 13-23 altitude range for the dense aggregates, and in the $25-30 \mathrm{~km}$ altitude range for fluffy aggregates, thus, close to the ones detected by LOAC and STAC (the LOAC typologies indicate that indeed the optically-absorbing particles dominate the aerosol-enhanced layers).

It seems difficult to determine the origin of the particles inside the enhancements based only on the altitude of the layers and thus on the porosity of the particles. Carbonaceous particles coming from space or emitted from the Earth's surface can be either compact or fluffy depending on their production mode and on their aging in the atmosphere. 


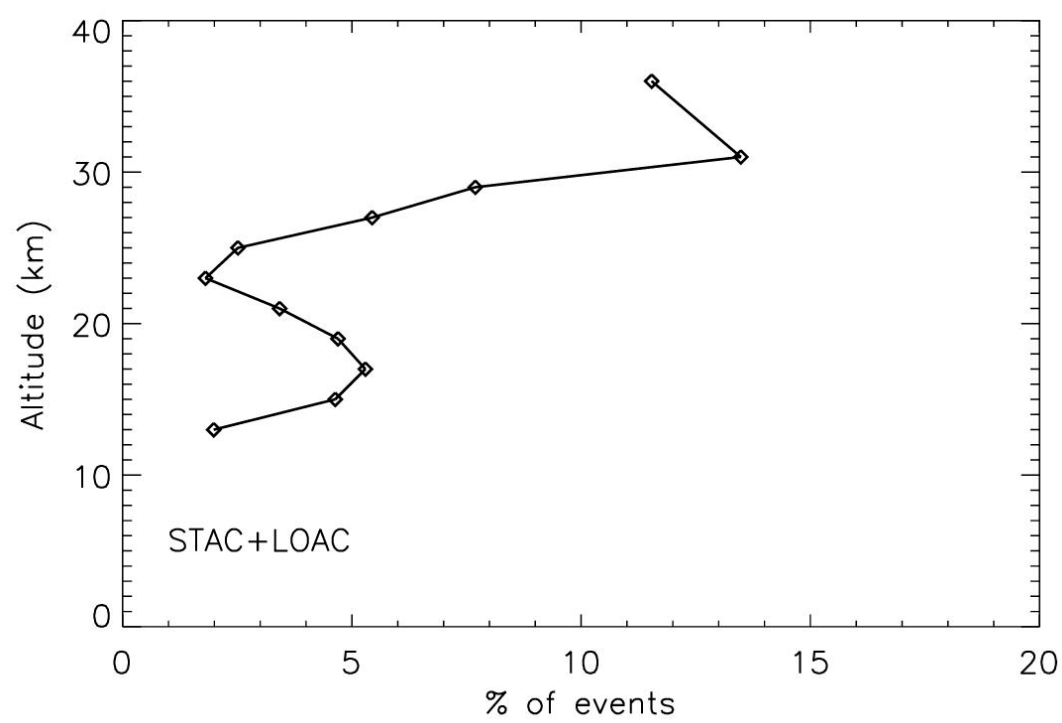

Figure 12. Evolution with altitude of the percentage of concentration enhancement events detected by the Stratospheric and Tropospheric Aerosols Counter (STAC) and LOAC aerosol counters during balloon flights.

\subsection{Background Concentrations for Large NSPS}

LOAC can be tentatively used to estimate the background content of large particles with sizes ranging from several $\mu \mathrm{m}$ up to $50 \mu \mathrm{m}$, which are obviously NSPs, since large pure sulfuric acid droplets cannot exist in the stratosphere. These particles are usually expected to come from space (interplanetary dust and meteoroid debris), with possible growth by sulfuric acid condensation consequently to their descent in the stratosphere [90].

Considering the number of flights per year, the balloon ascent speed $\left(\sim 5 \mathrm{~m} \cdot \mathrm{s}^{-1}\right)$ and the pump flow $\left(\sim 2 \mathrm{~L} \cdot \mathrm{min}^{-1}\right)$, LOAC has sampled about 1 to $2 \mathrm{~m}^{3}$ of air per year in the $15-35 \mathrm{~km}$ altitude range. Since 151 flights were performed in the mid-2013-2019 period, it seems statistically reasonable to calculate the mean values of particle concentrations for three broad size classes $(5-7.5 \mu \mathrm{m}, 10-17.5 \mu \mathrm{m}, 20-50 \mu \mathrm{m})$ in layers of $5 \mathrm{~km}$ width. Figure 13 presents the altitude dependence of the mean concentrations; the horizontal bars represent the interannual variability. The concentrations decrease by about a factor of two from 15 to $35 \mathrm{~km}$ for the three size classes. In the middle stratosphere, the mean concentrations of particles having sizes of about $5 \mu \mathrm{m}, 10 \mu \mathrm{m}$, and $20 \mu \mathrm{m}$ are of about 50,10, and below 10 particles $\mathrm{m}^{-3}$, respectively. 


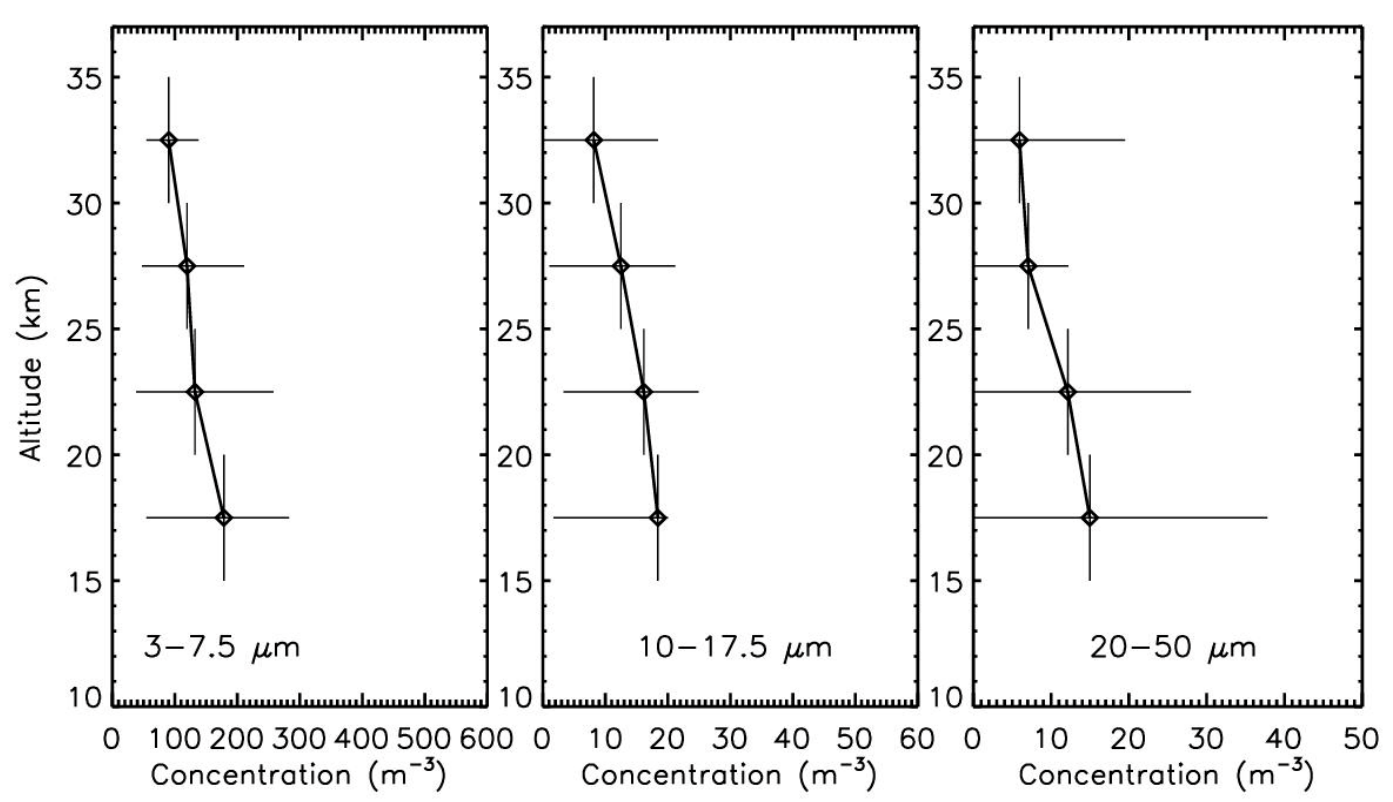

Figure 13. Altitude dependence of the concentrations of the large particles detected by LOAC for the 2013-2019 period, for three size classes; the dots represent the mean values, and the horizontal bars represent the interannual variability.

\section{Discussion on the Spatial and Temporal Variability, Size, and Composition of NSPs}

During its regular flights, LOAC has detected concentration enhancements that are associated with NSPs and the presence of large particles in significant amounts. It is then necessary to investigate whether such kind of detections are confirmed by other instruments and previous works, and what could be the origin of such particles.

Several authors have reported local enhancements of NSPs concentrations in the stratosphere. These sporadic features are highly variable in terms of concentrations, residence times (i.e., from the scale of days to months), and proposed origins. An overall picture may seem to be delicate to establish because results on concentrations, size distributions and compositions stem from different works and methodologies and can concern particles of different origins and compositions. Some trends on the vertical dependence of NSPs, on the occurrence of sporadic concentration enhancements, on the size distribution, and on the chemical composition of the particles, are nevertheless pointed out.

\subsection{Vertical Dependence of NSPS}

In the middle and upper stratosphere, the Stratospheric Aerosol and Gas Experiment (SAGE) II satellite extinctions have been compared to the Whole Atmosphere Community Climate Model (WACCM) calculations (assuming only liquid aerosols [59]. A strong enhancement of measured extinctions has been found above $30 \mathrm{~km}$ altitude on average; a mean extinction value of about $5 \cdot 10^{-6} \mathrm{~km}^{-1}$ is found at $40 \mathrm{~km}$ altitude, although model calculations provide a zero value for sulfate aerosols. The extinction excess is likely associated with the contribution of meteoroid smoke particles, coming from the disintegration of meteoroid and recondensation processes [90-94], while an external and/or internal mixture of smoke particles and sulfate aerosols occur at lower altitudes. The ubiquitous presence of non-fully optically transparent particles was also found in the extinction measurement of the Global Ozone Monitoring by Occultation of Stars (GOMOS/) instrument on the Envisat satellite, for which the wavelength dependence of the extinctions strongly differed from the one expected for pure liquid aerosols only [51]. The presence of light-absorbing particles in the middle stratosphere was also detected from sparse balloon measurements with extinctions and radiance measurements [13,33]; these particles could be either internally or externally mixed with the sulfate aerosols. Nevertheless, such remote sensing measurements do not provide the precise nature and composition of these 
particles, so-called "soot" by the authors although "strongly optically-absorbing material" could be more appropriate (the terminology for describing such light-absorbing carbons is reviewed in [95]).

The presence of soot and BC in the lower stratosphere was detected below $20 \mathrm{~km}$ altitude using wire impactors on airplane $[29,30,32]$. BC aerosol number density could be of about $1 \%$ of the total aerosol content in the lower stratosphere. On the other hand, using light scattering and incandescence measurement techniques, the concentration of light-absorbing particles (attributed to BC and particles with metals) was estimated in the $0.2-0.8 \mu \mathrm{m}$ size range above the tropopause in the northern polar vortex [10]. More than 10 particles $\mathrm{cm}^{-3}$ were found in that size range, with higher contents than for extra-vortex air. The light absorbing particles with size in the $0.2-0.3 \mu \mathrm{m}$ size range are more abundant by a factor of 10 than the non-light absorbing particles; conversely, non-light absorbing particles larger than $0.3 \mu \mathrm{m}$ are more abundant, up to a factor of 10 , than light absorbing particles. Using counting techniques and heating to remove the volatile material, a much higher fraction of particles containing non-volatile residues was found inside than outside the polar vortex [11]. These particles could result from the downward transport of refractory meteoritic material within the polar vortex from the mesosphere to the lower stratosphere as concluded from aerosol collections $[14,36]$.

At other latitudes, two categories of NSPs has been derived for altitudes below $20 \mathrm{~km}$ at different latitudes, using Particle Analysis by Laser Mass Spectrometry (PALMS) observations [39,40]: NSP with metal compounds proposed to probably originate from vaporized and condensed meteoritic material, and NSP with mixture of sulfate and organic particles. The second category corresponds to the main components of aerosols in the mid-latitude and tropical lower stratosphere. These observations agree with the results in the northern tropical region [35] where $40 \%$ of BC particles showed evidence of internal mixing. Then, the average fraction of carbonaceous material in the stratospheric particles decreases rapidly with increasing altitude.

All these measurements, including those of LOAC, has showed that, indeed, NSPs can be found in the whole stratosphere, but in varying concentrations, depending on the origin and the transport of such particles.

\subsection{Sporadic Strong Concentration Enhancements in the Stratospheric Aerosol Content Related to Reported Events}

Sporadic concentration enhancements have been reported at different altitudes, having different identified origins: biomass burning, pollution, volcanic eruption, rocket motor exhaust plumes, and meteoroid disintegration.

Plumes of carbonaceous particles originating from North American forest burning in July 2002 have been detected up to an altitude of $16 \mathrm{~km}$ by Laser Mass spectrometry and counting measurement [38]. The increase concentration is about seven times higher than background conditions. The origin of the particles was confirmed with correlated CO measurements. Short-living and local increases up to a factor 2.5 in aerosol extinction measurements related to intense biomass burning have been seen by the SAGE III space-borne instrument over Australia at the beginning of 2003 [55]. These particles can be injected in the lower stratosphere by the pyro-convection process occurring at the top of the dense smoke clouds [54]. Ground-based lidar measurements at Observatoire de Haute Provence, France $\left(43.9^{\circ} \mathrm{N}, 5.7^{\circ} \mathrm{E}\right)$ and space-borne lidar measurements from the CALIOP/Calipso instrument have detected plumes of fire particles between 18 and $20 \mathrm{~km}$ altitude over southern France, coming from wildfires in northwest Canada and United States in August 2017 [21]. The scattering ratio at $532 \mathrm{~nm}$ wavelength is about 10 times higher than for background conditions. Moreover, a layer of soot particles at $15-16 \mathrm{~km}$ altitude coming from these wildfires, and well identified by the specific wavelength dependence of the lidar depolarization ratios, were observed in Germany over Leipzig $\left(51.3^{\circ} \mathrm{N}, 12.4^{\circ}\right)$ on 22 August 2017 [22]. Such particles were also detected up to an altitude of $23 \mathrm{~km}$ by the European Aerosol Research lidar Network [23]. These measurements have shown that local enhancements of fire plume particles can be detected several thousands of $\mathrm{km}$ from their sources, impacting the stratospheric aerosol content at the hemispheric scale with an amplitude (both in terms 
of aerosol content and residence time) comparable to that of a moderate volcanic eruption [96]. Satellite data show that the NSPs from this specific fire plume event remained detectable in the northern hemisphere stratosphere over a period of about 8 months [84]. Nevertheless, the morphology and composition of these particles have not been determined so far.

Local intrusions of particles attributed to BC have also been reported from CALIOP/Calipso in the lower stratosphere during the monsoon season over India, with few sparse enhancements by $20-30 \mathrm{~km}$ altitude [63]. The origin of such particles is not well-established, though these authors propose them to originate from airplanes traffic before being vertically transported.

Moderate volcanic eruptions can inject aerosols directly into the lower stratosphere. Some ashes can be present, as observed after the Kelud eruption (February 2014) in the lower tropical stratosphere [62]. Ashes were detected by analysis of CALIOP/Calipso space-borne observation in comparison with in situ measurements from optical backscatter aerosols sounders and optical aerosols counters. The residence time of ash material in the stratosphere depends on the injection altitude and on the size of the particles. Values of several weeks are expected due to sedimentation [56]. However, the residence time of ash material is not clearly determined especially when mixing or coating processes with sulfate occur.

Rockets produce solid particles that can be found in the stratosphere. Campaigns of in situ particle counter measurements were conducted on board airplanes in 1996 and 1997 to detect the alumina particles in the motor exhaust plumes. Measurements in the stratosphere between 17 and $19.5 \mathrm{~km}$ showed strong concentration enhancements of about a factor of 100 with respect to the nearby background conditions [97].

The ground-based twilight photometric observations have shown accumulation layers at altitudes of $30 \mathrm{~km}$ and $54 \mathrm{~km}$ on 20-21 November, 1998, during the Leonids meteor shower [98]. Large and thin dust accumulation layers were also detected between 20 and $50 \mathrm{~km}$ altitude on 21-26 November 2001, 25-27 November 2002, and 16-17 November 2003, during the Leonids [16,98]. As opposed to permanent meteor showers visible on every year at a given epoch, the Leonids may produce periodic meteor storms for about 3 to 4 years every 33 years. The enhancements in the twilight light intensities are of tens of percent. Such layers were observed 4 to 8 days after the peak meteor activity, but with a strong variability from one day to another for the altitude and the amplitude of the vertical structures. The authors state that a couple of weeks after the meteor activity the atmosphere had recovered its normal dust distribution profile, although a dust layer at $30 \mathrm{~km}$ altitude could have persisted. Such observations of transient layers need to be confirmed for other occasional and major meteor storms.

Some lidar observations in the Arctic during the 2000-2001 winter have fortuitously detected strong concentration enhancements from 25 to $40 \mathrm{~km}$ altitude, with strong spatial and temporal variability over a few days [19]. It has been proposed that they could originate from meteoritic debris after the disintegration of a meteoroid in the atmosphere or from debris of condensed rocket fuel. A strong particle enhancement was also observed around $30 \mathrm{~km}$ altitude, which was well identified as coming from the disintegration of a large meteoroid of a few meters in size on 3 September 2004, over Antarctica, with residence time from weeks to months [18].

Major meteoroid disintegrations can produce strong enhancements in aerosol concentrations initially localized at the altitude of the disintegration and then progressively dispersed by the global circulation. The Chelyabinsk meteor event on 15 February 2013, started with an enhanced aerosol loading in the $30-35 \mathrm{~km}$ altitude range, as seen in extinction measurements of the Optical Spectrograph and InfraRed Imager System (OSIRIS) instrument on the Odin satellite [59]. Ozone Mapping and Profiler Suite (OMPS) instrument onboard the Suomi National Polar-orbiting Partnership (NPP) satellite has detected an extinction enhancement of a factor 10 at $40 \mathrm{~km}$ altitude and a few $\mathrm{km}$ width. It has then monitored the motion of the associated ring-shaped plume in the mid-latitude stratosphere over at least 3 months through its dispersion and its sedimentation from 40 to $30 \mathrm{~km}$ altitude [57]. 
All of these various NSP enhancements, typically of a factor 10 compared to background conditions, and with vertical extent of few hundreds to few $\mathrm{km}$, seem to be similar to those detected by LOAC and STAC, and confirm that different mechanics can be proposed for their origin and transport.

\subsection{Size Distribution}

The size distribution of NSPs in the stratosphere, which could provide clues to the origin of the particles, has up to now been poorly estimated. Only sparse direct measurements have been obtained mainly by in situ collectors and by optical counters. Among them, the concentration enhancements of NSPs detected by LOAC are in some cases composed of small particles only, and for other cases composed of large particles up to tens of $\mu \mathrm{m}$, showing the variability of their size distribution.

Historically, combining model calculations of the meteoroid ablation around $80 \mathrm{~km}$ altitude and airplane collected particles [99], a bimodal repartition of the solid material in the middle stratosphere has been proposed [100]. The authors said that particles below $0.1 \mu \mathrm{m}$ could come from the smoke particles while the largest particles could originate from interplanetary dust and meteoroid debris. Nevertheless, particles coming from space could be a fraction of the NSPs content since particles coming from Earth must be also considered.

In the lower stratosphere, different size distributions have been detected. In the Arctic, the optically absorbing particles can dominate for size below $0.3 \mu \mathrm{m}$ [10]. The rocket engine plumes measurements, for the two cases-studies in the 17-19.5 km altitude range, have shown a three modal distribution centered below $0.01 \mu \mathrm{m}$, around $0.1 \mu \mathrm{m}$ and around $2 \mu \mathrm{m}$ [97]. The fine volcanic ashes in the lower tropical stratosphere after the Kelud eruption have been estimated to be below $0.6 \mu \mathrm{m}$ in optical diameter [62]. The PALMS instrument has shown that globally the NSPs have an aerodynamical diameter below $1 \mu \mathrm{m}$ [40]; however, the instrument works only in the $0.2-2 \mu \mathrm{m}$ size range, and the aerodynamical diameter can significantly differ from the optical diameter used by the optical aerosol counters.

The particles collected from airplanes present a wide variety of shapes and sizes. Soot particles are in general smaller than $1 \mu \mathrm{m}$, in compact or chain-like shapes [29,30,32]. Submicron to 10- $\mu \mathrm{m}$ particles of vastly different shapes and natures were collected in the stratospheric polar vortex at altitudes up to $21 \mathrm{~km}$ [14]. Large particles, from a few $\mu \mathrm{m}$ to a few tens of $\mu \mathrm{m}$, are also present in the NASA aircraft dust collections [72,101] and in the balloon-borne dust collection by the Dust from the Upper Stratosphere Tracking Experiment and Retrieval (DUSTER) instrument [47]. The concentrations of particles greater than a few $\mu \mathrm{m}$ could be in the $10^{-6}-10^{-3}$ particles $\mathrm{cm}^{-3}$ range.

\subsection{Particles Chemical Composition}

LOAC provides the typology but not the chemical composition of the particles. Nevertheless, we propose here to summarize the results reported by various authors on the compositions of NSPs, and on their proposed interpretations for their origins discussed in Section 4.

In the lower stratosphere, the presence of an aerosol population with mixed sulfuric acid and metals, principally $\mathrm{Fe}, \mathrm{Na}, \mathrm{K}, \mathrm{Al}, \mathrm{Cr}, \mathrm{Ni}$ atoms, has been derived from airborne mass-spectrometry observations [37,39]. Soot or BC particles have been also detected, in agreement with other observations [30,32]. Moreover, the composition of collected particles below $0.2 \mu \mathrm{m}$ strongly differs from that of the common pure sulfate aerosols [26]; the main population of these ultrafine particles is composed of carbon, with traces of $\mathrm{S}, \mathrm{Na}$, metal sulfates, and chlorides. These particles could have a terrestrial origin.

The analysis of hundreds of airplane-collected NSPs in the polar winter lower stratosphere [14] has shown that refractory particles greater than $0.5 \mu \mathrm{m}$ mostly consist of silicate, silicate/carbon mixtures, Fe-rich, Ca-rich, and complex metal mixtures including aluminum. The detection of metallic material within some mixed particles might indicate the effect of high temperatures during the formation process, but is not in line with the results from airborne mass spectrometers that might rather suggest diluted Fe atoms [39]. On the other hand, particles below $0.5 \mu \mathrm{m}$ are mostly composed of soot [14]. 
Most of these submicron carbonaceous refractory particles are completely amorphous and only a few particles are ordered with graphene sheets [15]; minor traces of $\mathrm{Si}, \mathrm{Fe}, \mathrm{Cr}, \mathrm{Ni}$ are often found in these carbonaceous particles. No difference has been highlighted in terms of size, nanostructure and elemental composition for such particles either collected inside and outside the polar vortex at least for the period of these observations, i.e., winter 2010. Some of these particles could come from space, and the others could have a terrestrial origin.

Amongst the huge number of particles collected in the lower stratosphere by NASA airplanes, or retrieved in the return capsule of Stardust at comet 81P/Wild, or directly collected in Antarctica snows, numerous particles of cometary origin have been identified and analyzed. Chondritic Porous Interplanetary Dust Particles in the stratosphere (CP-IDPs) and Ultra Carbonaceous Antarctica Micro-Meteorites (UCAMMs) are composed of optically black aggregates of submicron components with a wide range of porosities, and are significantly enriched in carbon in the form of pristine and complex organic molecules [102-105]. Similarities between these particles and cometary dust particles have been progressively suggested through cometary flybys or analyses of Stardust samples from comet 81P/Wild 2 [106], and have been established through results of on the composition and physical properties of cometary dust studied during the long-duration Rosetta mission to comet 67P/Churyumov-Gerasimenko $[107,108]$. Such irregular and fluffy cometary dust particles partially survive atmospheric entry and transit in the stratosphere. They consist of more than $70 \%$ of organic molecules in volume, mixed with tiny flakes of minerals [109-111].

In the middle stratosphere, $\mathrm{Cl}, \mathrm{S}, \mathrm{Ti}, \mathrm{Fe}, \mathrm{Br}, \mathrm{Ni}, \mathrm{Zr}, \mathrm{Zn}, \mathrm{Sr}$, and $\mathrm{Cu}$ elements have been found in collected NSPs (elements having atomic number lower than 16 could not be detected in their analysis), with $2 / 3$ of the 23 analyzed non-graphitic particles ranging from $\mathrm{Al}$ rich silicates to almost pure $\mathrm{Fe}$, and one particle consisting almost exclusively of Ba and S [46]. Finally, the DUSTER collection has shown also two $100 \mu \mathrm{m}$ spheres with O-Si-Na-Mg-Ca composition [47], and the presence of pure carbon particles, aggregates of $\mathrm{CaCO}$ and $\mathrm{CaCO}_{3}$ grains [48]. The origin of these particles is not well established.

\section{Discussion about Possible Sources of NSPs, from Ground to Space}

\subsection{Context}

LOAC measurements, together with the other measurements discussed in the previous section, indicate that indeed a large variety of NSPs are present in the stratosphere. Some reported detections have been related to well-identified events (volcanic eruptions, wildfires, meteoroid disintegration), with high variabilities in their temporal and spatial content in qualitative agreement with those detected by STAC and LOAC. The strong vertical, temporal, and typological variabilities of NSPs detected from one flight to another seem to confirm the complexity of the stratospheric NSP content and the difficulty to propose a global view of particle origins. All of the information derived from the various sources of measurements, including LOAC, appears difficult to reconcile quantitatively in terms of NSP concentrations, size distributions, and compositions. In fact, most of the measurements could represent snapshots on specific geophysical conditions or of specific events.

Multiple sporadic and permanent sources of NSPs must be considered, coming from Earth (emitted from the surface or produced within the atmosphere) and from space. In particular, some papers presented in the previous sections have mentioned material coming from meteoroid disintegration, which is indeed a source, but did not always consider porous carbonaceous interplanetary dust particles as mainly originating from comets on prograde orbits. The dust particles from such comets would have a lower velocity relative to the Earth than dust particles on retrograde orbits, and thus, could more easily survive the atmospheric entry. The recent results of the Rosetta mission on comet 67P/Churyumov-Gerasimenko have provided a ground-truth for such dust particles. Thus, dust particles resulting from meteoroid disintegration could differ in size, shape, and composition of those coming from comets within the interplanetary dust cloud. 


\subsection{Sources from Earth's Surface}

The presence of volcanic ashes in the stratosphere associated with some volcanic eruptions is due to an explosive process directly injecting the material into the stratosphere. No mechanism of injection of ashes in the troposphere with subsequent transport to the stratosphere by the Brewer-Dobson circulation has been reported so far.

Major biomass burnings, from natural or anthropogenic origin, are more frequent and can produce thick clouds of carbonaceous particles that can reach the tropopause level. These particles can reach the lower stratosphere through direct injection by cross-tropopause pyro-convection events or through transport associated with overshooting convection enhanced by fire activity [38,112-114]. Moreover, they might be injected directly in the stratosphere through the tropopause folds.

In addition to these sporadic events, periodic atmospheric mechanisms can consist in a source of NSPs at a global scale. In particular, the Asian summer monsoon and the associated Asian Monsoon Anticyclone (AMA) can largely determine the composition of the Upper Troposphere/Lower Stratosphere (UTLS). An accumulation of aerosols has been pointed out inside the AMA and is present each year from June to September in the $\sim 15-18 \mathrm{~km}$ altitude range in the UTLS region. This layer, known as the Asian Tropopause Aerosol Layer (ATAL) [64,115], is likely to be associated with Asian emissions of anthropogenic pollutants, such as sulfur dioxide and volatile organic compounds, building a population of NSPs consisting of a mixture of sulfates and organic material both as primary and secondary organic aerosols. The ATAL is sustained by the convective activity of the Asian monsoon as indicated by global model simulations [116,117]. However, the precise composition, variability, trend, and budget of the ATAL are still largely uncertain, and are currently under investigation. After the breakup of the AMA, the signature of the ATAL is detectable on the extratropical aerosol budget in the northern hemisphere [118], indicating that combined processes, i.e., emissions in Asia, convective activity, and general circulation, impact part of the global stratospheric NSP population.

\subsection{Production within the Atmosphere}

The rare events of the disintegration of large meteoroids with sizes above about $10 \mathrm{~m}$ occur several times per century and can produce a large plume of dust that can take months to sediment, as for the Chelyabinsk meteor in February 2013. Disintegration of meter-sized meteoroids is detected several times per year and can produce local layers of dust. Moreover, partial or total disintegration of $\mathrm{cm}$-size meteoroids could occur daily. The disintegration altitude depends on the velocity entry, the incidence angle of the trajectory, the density, and the composition of the meteoroid (minerals like olivine, iron, ices, and complex organics $[119,120])$. The probability of crossing such a layer fortuitously during in situ measurements could be low but non-negligible.

Meteoroid ablation may begin by altitudes up to about $180 \mathrm{~km}$. Layers of minerals and metals are then present in thermosphere between 100 and $80 \mathrm{~km}$ altitude from the recondensation process $[90,92,94]$ that produce nanometer-sized smoke particles [121]. Such NSPs need to be aggregated or to grow through the condensation of sulfuric acid when transported downward to produce particles of at least of $150 \mathrm{~nm}$ to be optically detectable by optical aerosol counters.

The rockets exhaust and the disintegration of satellites subsequently to their atmospheric entry (more than one hundred per year) produce locally alumina, hydrocarbon, and metallic debris [97,122]. The local content of these specific refractory NSPs increases and measurements could be fortuitously conducted inside a plume [123]. Such particles can be also collected far from their sources at different times of their transit in the atmosphere during which their physical properties are likely to evolve. As a result, some of them have been found to be mixed with particles having other origins [14].

Compact particles and filaments having 5-10 $\mu \mathrm{m}$ in size and up to several $\mathrm{mm}$ long, composed of carbon polymeric nanocomposites, can be produced in ambient air inside plasmas [124]. Such conditions could occur during atmospheric entries of meteoroids and satellites/rocket debris, during storm lightning [125], and perhaps during high-energy phenomena in the stratosphere, such as blue jets and sprites. These nanocomposites are characterized by the presence of Fe-Ni-Cr elements. Some 
of the grains collected by [14] present the same composition; it could be just a coincidence or some of these particles could be indeed nanocomposites produced within the atmosphere instead of meteoritic material. Moreover, dusty plasma spherical particles typically in the 0.1-1.5 $\mu \mathrm{m}$ size range can be produced in glow discharge [126] as those encountered in the atmosphere. Layers of such particles (spheres and filaments) could produce significant local concentration enhancements of micron(s)-sized aerosols, perhaps detected by LOAC.

Hypothetical long-lived volcanic soot particles could be also produced in the stratosphere due to thermal decomposition of methane from geothermal/volcano sources [127-129], but this highly speculative process needs further studies to be confirmed.

Finally, if soot particles emitted from airplane engines can be directly injected in the lower stratosphere during their cruise, their contribution is expected to be low with respect to other sources coming from natural and anthropogenic biomass burning $[10,35,130]$.

\subsection{Dust from Space}

As previously mentioned, the cometary material could differ from meteoroid material; thus, we propose below a short review of the physical properties of the dust in the interplanetary cloud.

The Earth orbits around the Sun within the interplanetary dust cloud, which is a wide and flattened circumsolar cloud built of dust particles [105]. Their sizes range from a few tens of nm to a few $\mathrm{mm}$, with dominant sizes around hundreds of $\mu \mathrm{m}$. The spatial density of the interplanetary dust cloud increases towards the Sun and its near-ecliptic symmetry surface, although it remains extremely low, with about 5 to 20 particles of about $10 \mu \mathrm{m}$ size per $\mathrm{km}^{3}$ in the vicinity of the Earth [131].

These grains slowly spiral towards the Sun (under Poynting-Robertson effect); the persistence of the interplanetary dust cloud indicates that a more or less continuous replenishment takes place. Analysis of observations in the visible and infrared domains [132,133] and dynamical studies [134] indicate that most of the interplanetary dust particles reaching the Earth's vicinity are of cometary origin, with a contribution of about $85 \%$ of the total mass influx from short-period comets with a prograde motion, called Jupiter Family Comets (JFCs).

Dust particles of cometary origin, containing organic material, have long been understood to form meteoroid streams, such as the August Perseids from comet 109P/Swift-Tuttle. Besides, infrared observations have allowed the discovery of faint dust bands attributed to originate from asteroid collisions within the asteroid belt [135], and of narrow and elongated structures (so-called dust trails) along JFCs [136,137] produced by the ejection of large dust particles or pebbles from cometary nuclei.

Because of its sources of replenishment, the interplanetary dust cloud is not a featureless structure [138], although the dust particles are progressively randomly distributed. When interplanetary dust particles impact the Earth atmosphere, they induce the formation of sporadic meteors, annual meteor showers, or sporadic meteor storms from more recent dust particles injected in the interplanetary cloud. The flux of entry particles can be tens to hundreds of times higher than during background conditions during the main permanent meteor shower episodes; four main events may be mentioned, the Quadrantids (beginning of January), the Aquarids (beginning of May), the Perseids (mid-August), and the Geminids (mid-December).

As already suspected from comet 1P/Halley flybys in 1986, and established by the Rosetta mission with 67P/Churyumov-Gerasimenko in 2014-2016, the refractory component in comets is rich in high molecular-mass organics, possibly about $45 \%$ in mass and $70 \%$ in volume $[107,139,140]$. The flux of exogenous material from interplanetary dust entering in the Earth atmosphere is, thus, rich in complex organics. The dust particles ejected from the nucleus of 67P/Churyumov-Gerasimenko are porous aggregates covering a wide range of sizes, at least from tens to hundreds of $\mu \mathrm{m}$ [141], and of porosities with likely fractal structures $[108,142,143]$. The speed of interplanetary dust particles coming from JFCs and that impact the Earth's atmosphere are mostly low, around $15 \mathrm{~km} / \mathrm{s}$ range [134] or less.

The total amount of material entering the Earth atmosphere is still not well determined, with a daily value in the 5-270 tons range, depending on the various techniques used for the determination [91]; a 
mean value of about 100 tons per day is frequently assumed [101]. Considering the cosmic spherule accretion rate at South Pole, the Na and Fe flux measured in the upper mesosphere coming from the ablation of the incoming solid material, the satellite measurements of the interplanetary dust cloud radiation, and ablation-modeling calculations, dust coming from the JFCs could contribute to about 80 $\pm 17 \%$ of the dust mass entering the Earth atmosphere and estimated at $43 \pm 14$ tons per day [144]. Thus, a large fraction of NSPs commonly assumed to have a meteoroid origin could in fact originate from comets. It can be then suggested that the aggregated porous and complex organics-rich particles detected in the stratosphere $[14,15]$ could come from comets, not from asteroids, while silicate-rich particles could come either from comets or asteroids.

Nevertheless, two difficulties may arise for the detection and the identification of the incoming material and the identification of their origin. First, some dust particles may be broken during their atmospheric travel, producing a significant number of smaller particles, some of them being not detectable. Secondly, carbonaceous particles might originate either from space or from Earth and could have similar physical properties. The optical measurements we perform cannot distinguish between these two different origins.

About $10^{3}$ particles $\mathrm{m}^{-3}$ greater than $3 \mu \mathrm{m}$ in the lower stratosphere have collected during the Reconcile campaign inside the polar vortex below $21 \mathrm{~km}$ [14]. At such altitude, the LOAC concentration of particles greater than $5 \mu \mathrm{m}$ is below 150 particles $\mathrm{m}^{-3}$; the concentration for particles greater than $3 \mu \mathrm{m}$ increase to about 400 particles $\mathrm{m}^{-3}$ (although some of them could be liquid), which is not so far from the value obtained by [14].

Using the measurements obtained by [99], the concentration of interplanetary dust (or micrometeoroids) at $30 \mathrm{~km}$ was estimated to be of about $10^{-3}$ particles $\mathrm{m}^{-3}$ for sizes greater than $5 \mu \mathrm{m}$ [100]. On the other hand, the concentration of collected particles greater than $5 \mu \mathrm{m}$ by the DUSTER instrument during one balloon-flight at $38 \mathrm{~km}$ was of about one particle $\mathrm{m}^{-3}$ [48]. These concentrations are well below the LOAC mean value of about 50 particles. $\mathrm{m}^{-3}$.

All of these sparse measurements have sampled a small volume of the stratospheric air, which can cause some variability for the estimation of large particle's concentrations. These preliminary results show that more measurements will be needed to better estimate this content.

Some of these particles are often classified as "meteoroid material", based on the presence of Fe, $\mathrm{Mg}, \mathrm{Ni}, \mathrm{Cr}, \mathrm{Na}$ in their compositions derived from collected samples or from in situ analysis [14,47]. Interplanetary dust, mainly originating from Jupiter Family Comets, must be also considered. Porous cometary dust particles with not too high relative velocities happen to reach the stratosphere [107], thus, they can contribute to the carbonaceous particles found in the stratosphere. Nevertheless, we may conclude that the presence of interplanetary material in the stratosphere is dramatically overestimated from the measurements performed inside the atmosphere since the detected concentrations are several orders of magnitude above the estimated concentration of material in space at Earth orbit, i.e., $10^{-8}$ particles $\mathrm{m}^{-3}$ for size greater than $10 \mu \mathrm{m}$ [131]. This last value might be tens or hundreds higher during meteor shower events and even more in case of meteoroid disintegrations inside the stratosphere, but still without reaching the stratospheric concentrations of large NSPs.

Many more in situ measurements of large particles will be necessary to better estimate the concentrations of large particles in the stratosphere. At present, we could propose some explanations to tentatively explain these discrepancies:

The flux and the size distribution of incoming material from space is strongly underestimated when considering measurements from space and model calculations. In particular, the size distribution estimated from impacts on exposed surfaces in space [65-67] could be inaccurate.

Some particles produced by the Chelyabinsk meteor disintegration could remain longer than expected in the stratosphere. This could (partly) explain some high concentrations values detected by LOAC since the beginning of the measurements in 2013 until the return to lower values at the beginning of 2017. 
The instruments (including LOAC) may have mainly detected material coming from the Earth during specific events, or produced inside the atmosphere, and transported to the middle stratosphere. These particles can remain in some accumulation layers [88] and even can agglomerate. We are in favor of this last explanation, since the concentrations decrease with increasing altitudes and the accumulation layers were detected by LOAC and STAC at the altitude range predicted by the modelling calculations. Nevertheless, material coming from space including carbonaceous cometary particles could be also present. Finally, the identification of the origin of the particles based on their composition only could be inaccurate. As an example, the nanocomposites produced inside the atmosphere [125] could have chemical elements similar to those found in meteorites or in interplanetary dust.

\section{Conclusions}

Even if a large variety of in situ and remote sensing measurements have been conducted under different atmospheric conditions, none of them can provide a comprehensive view describing the whole complexity of the stratospheric NSPs content. The sources are multiple and most of them are non-permanent. One can expect a strong variability of the chemical composition, the size, and the concentration of stratospheric particles from one session of measurements to another. Moreover, the particles are likely to be detected or collected at different stages of their life cycle from their emission to their removal from the atmosphere during which they are transformed (e.g., condensational growth, coagulation, inclusion). This complicates the determination of their origin, of their physical properties, and of the processes controlling the evolution of their size distributions and concentrations.

The LOAC balloon-borne optical counter has contributed to better understand the origin of the complexity of the NSPs content. It has confirmed the presence of enhanced layers in terms of concentration of submicron and sometimes larger particles in the lower and middle stratosphere. The six years of regular flights (2013-2019) have shown a strong spatial and temporal variability of such events, which does not seem to be correlated to the main annual meteor showers. At present, we hypothesize the presence of accumulation layers of terrestrial and atmospheric particles mainly controlled by the dynamical and photophoretic effects, superimposed on the contributions of the meteoroid disintegrations, and of the entering interplanetary dust material coming from comets. The relative contribution of these various sources is not yet well determined.

Although regular LOAC flights can be continued to evaluate the variability of aerosols concentrations and the presence of NSPs, current optical aerosols counters cannot be used alone to better evaluate the complex content of NSPs because of their limited horizontal coverage and the absence of accurate determination of the particles' composition. New light instrumentation will be needed to perform many more flights to accurately document the NSPs in different conditions (background conditions, polar vortex, volcano eruption, strong meteoritic disintegration) and to be able to provide the average percentage of the different materials in the NSPS. Such instrumentation must be easy to launch under low-cost weather balloons. Moreover, small poly-instrumented gondolas could be proposed to measure the stratospheric aerosol content at the same time in the same air mass. These instruments could be mass-spectrometers and collecting devices for the determination of the composition of the particles, but also optical instruments (e.g., nephelometer) performing measurements at several scattering angles to retrieve simultaneously the size and the refractive index of the particles, as done, for example, at ground with the PRopriétés Optiques des GRains Astronomiques et Atmosphériques (PROGRA2) laboratory instrument [145,146].

Long-duration (and thus bigger) balloons in flight from weeks to months, with daily vertical excursions, and carrying a poly-instrumented gondola, could be also useful to better evaluate the temporal and spatial variability of NSPs. The MIR (French acronym "Montgolfiere Infra Rouge") developed and used in the past by the French Space Agency CNES could be a well-adapted balloon for this purpose [147]. Aerosols counters, nephelometers, and mass spectrometers can be associated on the same balloon platform together with a possible future instrument that can derive the isotopic 
composition of the solid material to better distinguish between the various sources, as proposed for carbonaceous particles by [148,149].

Remote-sensing measurements from future satellite platforms, such as the EarthCARE spaceborne lidar [150], coupled with balloon-borne measurements, could help to better identify the various natures of stratospheric aerosols and their transport, and to provide global statistics on the presence of local enhancements. Finally, a new in situ counting instrument along the Earth's orbit could be proposed to better estimate the size and the concentration of incoming material from space.

Author Contributions: J.-B.R. designed the LOAC experiment and processed the data. G.B. and D.V. participated in the improvement of the instrument and of the data processing, and in the data interpretation. A.-C.L.-R., S.B., A.M., P.R., and F.J. participated in the analysis of the origin of the aerosols and of their spatial and temporal variability. All authors have read and agreed to the published version of the manuscript.

Funding: The LOAC instruments were funded by the French Labex “Étude des géofluides et des VOLatils-Terre, Atmosphère et Interfaces-Ressources et Environnement" (VOLTAIRE) (ANR-10-LABX-100-01) managed by the University of Orleans. The STAC and LOAC flights were funded by the French Space Agency CNES.

Acknowledgments: We want to thank the CNES balloons launching team at Aire sur l'Adour, the MeteoModem Company for the flight for Ury (France), and Nelson Bègue and the LACy for the flights at Ile de la Réunion. We want to thank Marie-Agnès Courty for information concerning the local production of nanocomposite in the atmosphere, Andrei Vedernikov for fruitful discussion, the reviewers for their useful comments, and finally CNES for its support of the Rosetta mission and its scientific data analysis. Sergey Beresnev wants to thank the Ministry of Science and Higher Education of the Russian Federation, project \#FEUZ-2020-0057.

The STAC data are available at:

https://cds-espri.ipsl.upmc.fr/etherTypo/index.php?id=667\&L=1

The 2013 LOAC data are available at:

http://mistrals.sedoo.fr/?editDatsId=1017\&datsId=1017\&project_name=ChArMEx

The LOAC data from 2014 are available at:

https://cds-espri.ipsl.upmc.fr/etherTypo/index.php?id=1699\&L=1

Conflicts of Interest: The authors declare no conflict of interest.

\section{References}

1. Kremser, S.; Thomason, L.W.; von Hobe, M.; Hermann, M.; Deshler, T.; Timmreck, C.; Toohey, M.; Stenke, A.; Schwarz, J.P.; Weigel, R.; et al. Stratospheric aerosol-Observations, processes, and impact on climate. Rev. Geophys. 2016, 54, 278-335. [CrossRef]

2. Günther, A.; Höpfner, M.; Sinnhuber, B.-M.; Griessbach, S.; Deshler, T.; von Clarmann, T.; Stiller, G. MIPAS observations of volcanic sulfate aerosol and sulfur dioxide in the stratosphere. Atmos. Chem. Phys. 2018, 18, 1217-1239. [CrossRef]

3. Russell, P.B.; Livingston, J.M.; Pueschel, R.F.; Bauman, J.J.; Pollack, J.B.; Brooks, S.L.; Hamill, P.; Thomason, L.W.; Stowe, L.L.; Deshler, T.; et al. Global to microscale evolution of the Pinatubo volcanic aerosol derived from diverse measurements and analyses. J. Geophys. Res. 1996, 101, 18745-18763. [CrossRef]

4. Deshler, T.; Hervig, M.E.; Hofmann, D.J.; Rosen, J.M.; Liley, J.B. Thirty years of in situ stratospheric aerosol size distribution measurements from Laramie, Wyoming $\left(41^{\circ} \mathrm{N}\right)$ using balloon-borne instruments. J. Geophys. Res. 2003, 108, 4167. [CrossRef]

5. Solomon, S.; Daniel, J.S.; Nelly, R.R.; Vernier, J.-P.; Dutton, E.G.; Thomason, L.W. The persistently variable "background" stratospheric aerosol layer and global climate change. Science 2011, 333, 866-870. [CrossRef]

6. Jégou, F.; Berthet, G.; Brogniez, C.; Renard, J.-B.; Francois, P.; Haywood, J.M.; Jones, A.; Bourgeois, Q.; Lurton, T.; Auriol, F.; et al. Daugeron Stratospheric aerosols from the Sarychev volcano eruption in the 2009 Arctic summer. Atmos. Chem. Phys. 2013, 13, 6533-6552. [CrossRef]

7. Bègue, N.; Vignelles, D.; Berthet, G.; Portafaix, T.; Payen, G.; Jégou, F.; Benchérif, H.; Jumelet, J.; Vernier, J.-P.; Lurton, T.; et al. Long-range transport of stratospheric aerosols in the Southern hemisphere following the 2015 Calbuco eruption. Atmos. Chem. Phys. 2017, 17, 15019-15036. [CrossRef]

8. Vernier, J.-P.; Thomason, L.W.; Pommereau, J.-P.; Bourassa, A.; Pelon, J.; Garnier, A.; Hauchecorne, A.; Blanot, L.; Trepte, C.; Degenstein, D.; et al. Major influence of tropical volcanic eruptions on the stratospheric aerosol layer during the last decade. Geophys. Res. Lett. 2011, 38, L12807. [CrossRef] 
9. Deshler, T.; Richard Anderson-Sprecher, R.; Jäger, H.; Barnes, J.; Hofmann, D.J.; Clemesha, B.; Simonich, D.; Osborn, M.; Grainger, R.G.; Godin-Beekmann, S. Trends in the nonvolcanic component of stratospheric aerosol over the period 1971-2004. J. Geophys. Res. 2006, 111, D01201. [CrossRef]

10. Baumgardner, D.; Kok, G.; Raga, G. Warming of the Arctic lower stratosphere by light absorbing particles. Geophys. Res. Lett. 2004, 31, L06117. [CrossRef]

11. Curtius, J.; Weigel, R.; Vossing, H.-J.; Wernli, H.; Werner, A.; Volk, C.M.; Konopka, P.; Krebsbach, M.; Schiller, C.; Roiger, A.; et al. Observations of meteoric material and implications for aerosol nucleation in the winter Arctic lower stratosphere derived from in situ particle measurements. Atmos. Chem. Phys. 2005, 5, 3053-3069. [CrossRef]

12. Murphy, D.M.; Cziczo, D.J.; Hudson, P.K.; Thomson, D.S. Carbonaceous material in aerosol particles in the lower stratosphere and tropopause region. J. Geophys. Res. 2007, 112, D04203. [CrossRef]

13. Renard, J.-B.; Brogniez, C.; Berthet, G.; Bourgeois, Q.; Gaubicher, B.; Chartier, M.; Balois, J.-Y.; Verwaerde, C.; Auriol, F.; Francois, P.; et al. Vertical distribution of the different types of aerosols in the stratosphere, detection of solid particles and analysis of their spatial variability. J. Geophys. Res. 2008, 113, D21303. [CrossRef]

14. Ebert, M.; Weigel, R.; Kandel, K.; Günther, G.; Molleker, S.; Groob, J.-U.; Vogel, B.; Weinbruch, S.; Borrmann, S. Chemical analysis of refractory stratospheric aerosol particles collected within the arctic vortex and inside polar stratospheric clouds. Atmos. Chem. Phys. 2016, 16, 8405-8421. [CrossRef]

15. Schütze, K.; Wilson, J.C.; Weinbruch, S.; Benker, N.; Ebert, M.; Günther, G.; Weigel, R.; Borrmann, S. Sub-micrometer refractory carbonaceous particles in the polar stratosphere. Atmos. Chem. Phys. 2017, 17, 12475-12493. [CrossRef]

16. Padma Kumari, B.; Trigo-Rodriguez, J.M.; Londhe, A.L.; Jadhav, D.B.; Trimbake, H.K. Optical observations of meteoric dust in the middle stratosphere during Leonid activity in recent years 2001-2003 over India. Geophys. Res. Lett. 2005, 32, L16807. [CrossRef]

17. Padma Kumari, B.; Kulkarni, H.; Jadhav, D.B.; Londhe, A.L.; Trimbake, H.K. Exploring Atmospheric aerosols by twilight photometry. J. Atmos. Ocean. Technol. 2008, 25, 1600-1607. [CrossRef]

18. Klekociuk, A.; Brown, P.G.; Pack, D.W.; ReVelle, D.O.; Edwards, W.N.; Spalding, R.E.; Tagliaferri, E.; Yoo, B.B.; Zagari, J. Meteoritic dust from the atmospheric disintegration of a large meteoroid. Nature 2005, 436, 1132-1135. [CrossRef]

19. Gerding, M.; Baumgarten, G.; Blum, U.; Thayer, J.P.; Fricke, K.-H.; Neuber, R.; Fiedler, J. Observation of an unusual mid-stratospheric aerosol layer in the Arctic: Possible sources and implication for polar vortex dynamics. Ann. Geophys. 2003, 21, 1057-1069. [CrossRef]

20. Siebert, J.; Timmis, C.; Vaughan, G.; Fricke, K.H. A strange cloud in the Arctic summer stratosphere 1998 above Esrange (68 N.), Sweden. Ann. Geophys. 2000, 18, 505-509. [CrossRef]

21. Khaykin, S.M.; Godin-Beekmann, S.; Hauchecorne, A.; Pelon, J.; Ravetta, F.; Keckhut, P. Stratospheric smoke with unprecedentedly high backscatter observed by lidars above southern France. Geophys. Res. Lett. 2018, 45, 1639-1646. [CrossRef]

22. Haarig, M.; Ansmann, A.; Baars, H.; Jimenez, C.; Veselovskii, I.; Engelmann, R.; Althausen, D. Depolarization and lidar ratios at 355, 532, and $1064 \mathrm{~nm}$ and microphysical properties of aged tropospheric and stratospheric Canadian wildfire smoke. Atmos. Chem. Phys. 2018, 18, 11847-11861. [CrossRef]

23. Baars, H.; Ansmann, A.; Ohneiser, K.; Haarig, M.; Engelmann, R.; Althausen, D.; Hanssen, I.; Gausa, M.; Pietruczuk, A.; Szkop, A.; et al. The unprecedented 2017-2018 stratospheric smoke event: Decay phase and aerosol properties observed with the EARLINET. Atmos. Chem. Phys. 2019, 19, 15183-15198. [CrossRef]

24. Stein, B.; Del Guasta, M.; Kolenda, J.; Morandi, M.; Rairoux, P.; Stefanutti, L.; Wolf, J.P.; Wöste, L. Stratospheric aerosol size distributions from multispectral lidar measurements at Sodankylä during EASOE. Geophys. Res. Lett. 1994, 21, 1311-1314. [CrossRef]

25. Miffre, A.; Anselmo, C.; Geffroy, S.; Fréjafon, E.; Rairoux, P. Lidar remote sensing of laser-induced incandescence on light absorbing particles in the atmosphere. Opt. Exp. 2015, 23, 2347-2360. [CrossRef]

26. Scott, J.D.; Chittenden, D.M., II. Chemical composition of particles of $\mathrm{d}<0.20 \mathrm{~mm}$ in the lower stratospheric aerosol, Spring. J. Arkans. Acad. Sci. 2002, 56, 153-156.

27. Brownlee, D.E. Cosmic dust: Collection and research. Ann. Rev. Earth Planet. Sci. 1985, 13, 147-173. [CrossRef] 
28. Warren, J.L.; Zolensky, M.E. Collection and Curation of Interplanetary Dust Particles Recovered from the Stratosphere by NASA. In Analysis of Interplanetary Dust; Zolensky, M., Wilson, T., Rietmeijer, F., Flynn, G., Eds.; American Institute of Physics: New York, NY, USA, 1994; pp. 245-253.

29. Pueschel, R.F.; Black, D.F.; Snetsinger, K.G.; Hansen AD, A.; Verma, S.; Kato, K. Black carbon (soot) in the lower stratosphere and upper troposphere. Geophys. Res. Lett. 1992, 19, 1659-1662. [CrossRef]

30. Blake, D.F.; Kato, K. Latitudinal distribution of black carbon soot in the upper troposphere and the lower stratosphere. J. Geophys. Res. 1995, 100, 7195-7202. [CrossRef]

31. Pueschel, R.F.; Boering, K.A.; Verma, S.; Howard, S.D.; Ferry, G.V.; Goodman, J.; Allen, D.A.; Hamil, P. Soot aerosol in the lower stratosphere: Pole-to-pole variability and contributions by aircraft. J. Geophys. Res. 1997, 102, 13113-13118. [CrossRef]

32. Strawa, A.W.; Drdla, K.; Ferry, G.V.; Verma, S.; Pueschel, R.F.; Yasuda, M.; Salawitch, R.J.; Gao, R.S.; Howard, S.D.; Bui, P.T.; et al. Carbonaceous aerosol (soot) measured in the lower stratosphere during POLARIS and its role in stratospheric photochemistry. J. Geophys. Res. 1999, 104, 26753-26766. [CrossRef]

33. Renard, J.-B.; Ovarlez, J.; Berthet, G.; Fussen, D.; Vanhellemont, F.; Brogniez, C.; Hadamcik, E.; Chartier, M.; Ovarlez, H. Optical and physical properties of stratospheric aerosols from balloon measurements in the visible and near-infrared domains. III. Presence of aerosols in the middle stratosphere. App. Opt. 2005, 44, 4086-4095. [CrossRef] [PubMed]

34. Eidhammer, T.; Montague, D.C.; Deshler, T. Determination of index of refraction and size of supermicrometer particles from light scattering measurements at two angles. J. Geophys. Res. 2008, 113, D16206. [CrossRef]

35. Schwarz, J.P.; Gao, R.S.; Fahey, D.W.; Thomson, D.S.; Watts, L.A.; Wilson, J.C.; Reeves, J.M.; Darbeheshti, M.; Baumgardner, D.G.; Kok, G.L.; et al. Single-particle measurements of mid-latitude black carbon and light-scattering aerosols from the boundary layer to the lower stratosphere. J. Geophys. Res. 2006, 111, D16207. [CrossRef]

36. Weigel, R.; Volk, C.M.; Kandler, K.; Hösen, E.; Günther, G.; Vogel, B.; Grooß, J.-U.; Khaykin, S.; Belyaev, G.V.; Borrmann, S. Enhancements of the refractory submicron aerosol fraction in the Arctic polar vortex: Feature or exception? Atmos. Chem. Phys. 2014, 14, 12319-12342. [CrossRef]

37. Murphy, D.M.; Thomson, D.S.; Mahoney, M.J. In situ measurements of organics, meteoritic material, mercury, and other elements in aerosols at 5 to $19 \mathrm{~km}$. Science 1998, 282, 1664-1669. [CrossRef]

38. Jost, H.-J.; Drdla, K.; Stohl, A.; Pfister, L.; Loewenstein, M.; Lopez, J.P.; Hudson, P.K.; Murphy, D.M.; Cziczo, D.J.; Fromm, M.; et al. In situ observations of mid-latitude forest fire plumes deep in the stratosphere. Geophys. Res. Lett. 2004, 31, L11101. [CrossRef]

39. Murphy, D.M.; Froyd, K.D.; Schwarz, J.P.; Wilson, J.C. Observation of the chemical composition of stratospheric aerosol particles. Q. J. R. Meteorol. Soc. 2014, 140, 1269-1278. [CrossRef]

40. Renard, J.-B.; Berthet, G.; Robert, C.; Chartier, M.; Pirre, M.; Brogniez, C.; Herman, M.; Verwaerde, C.; Balois, J.-Y.; Ovarlez, J.; et al. Optical and physical properties of stratospheric aerosols from balloon measurements in the visible and near-infrared domains: Comparison of extinction, reflectance, polarization and counting measurements. Appl. Opt. 2002, 41, 7540-7549. [CrossRef]

41. Berthet, G.; Renard, J.-B.; Catoire, V.; Chartier, M.; Robert, C.; Huret, N.; Coquelet, F.; Bourgeois, Q. Remote sensing measurements in the polar vortex: Comparison to in situ observations and implications for the simultaneous retrievals and analysis of the $\mathrm{NO}_{2}$ and $\mathrm{OClO}$ species. J. Geophys. Res. 2007, 112, D21310. [CrossRef]

42. Berthet, G.; Renard, J.-B.; Brogniez, C.; Robert, C.; Chartier, M.; Pirre, M. Optical and physical properties of stratospheric aerosols from balloon measurements in the visible and near-infrared domains: Analysis of aerosol extinction spectra from the AMON and SALOMON balloonborne spectrometers. Appl. Opt. 2002, 41, 7522-7539. [CrossRef]

43. Mishchenko, M.I.; Hovenier, J.W.; Mackowski, D.W. Single scattering by a small volume element. J. Opt. Soc. Am. A 2004, 21, 71-87. [CrossRef]

44. Renard, J.-B.; Tripathi, S.N.; Michael, M.; Rawal, A.; Berthet, G.; Fullekrug, M.; Harrison, R.G.; Robert, C.; Tagger, M.; Gaubicher, B. In situ detection of electrified aerosols in the upper troposphere and stratosphere. Atmos. Chem. Phys. 2013, 13, 11187-11194. [CrossRef]

45. Füllekrug, M.; Diver, D.; Pinçon, J.-L.; Phelps AD, R.; Bourdon, A.; Helling, C.; Blanc, E.; Honary, F.; Harrison, R.G.; Sauvaud, J.-A.; et al. Energetic Charged Particles Above Thunderclouds. Surv. Geophys. 2013, 34, 1-41. [CrossRef] 
46. Testa, J.P., Jr.; Stephens, J.R.; Berg, W.W.; Cahill, T.A.; Onaka, T.; Nakada, Y.; Arnold, J.R.; Fong, N.; Sperry, P.D. Collection of microparticles at high balloon altitudes in the stratosphere. Earth Planet. Sci. Lett. 1990, 98, 287-302. [CrossRef]

47. Ciucci, A.; Palumbo, P.; Brunetto, R.; Della Corte, V.; De Angelis, S.; Rotundi, A.; Rietmeijer, F.J.M.; Zona, E.; Colangeli, L.; Esposito, F.; et al. DUSTER (Dust in the Upper Stratosphere Tracking Experiment and Retrieval) preliminary analysis. Mem. Soc. Astron. Ital. 2008, 75, 282-287.

48. Della Corte, V.; Rietmeijer, F.J.M.; Rotundi, A.; Ferrari, M.; Palumbo, P. Meteoric CaO and carbon smoke particles collected in the upper stratosphere from an unanticipated source. Tellus B 2013, 65, 20174. [CrossRef]

49. Bingen, C.; Fussen, D.; Vanhellemont, F. A global climatology of stratospheric aerosol size distribution parameters derived from SAGE II data over the period 1984-2000: Reference data. J. Geophys. Res. 2004, 109, D06202. [CrossRef]

50. Vanhellemont, F.; Fussen, D.; Mateshvili, N.; Tétard, C.; Bingen, C.; Dekemper, E.; Loodts, N.; Kyrölä, E.; Sofieva, V.; Tamminen, J.; et al. Optical extinction by upper tropospheric/ stratospheric aerosols and clouds: GOMOS observations for the period 2002. Atmos. Chem. Phys. 2010, 10, 7997-8009. [CrossRef]

51. Salazar, V.; Renard, J.-B.; Hauchecorne, A.; Bekki, S.; Berthet, G. A new climatology of aerosols in the middle and upper stratosphere by alternative analysis of GOMOS observations during 2002. Intern. J. Remote Sens. 2013, 34, 4986-5029. [CrossRef]

52. Thomason, L.W.; Ernest, N.; Millán, L.; Rieger, L.; Bourassa, A.; Vernier, J.-P.; Manney, G.; Luo, B.; Arfeuille, F.; Peter, T. A global space-based stratospheric aerosol climatology 1979-2016. Earth Syst. Sci. Data 2018, 10, 469-492.

53. Bourassa, A.E.; Rieger, L.A.; Lloyd, N.D.; Degenstein, D.A. Odin-OSIRIS stratospheric aerosol data product and SAGE III intercomparison. Atmos. Chem. Phys. 2012, 12, 605-614. [CrossRef]

54. Fromm, M.; Servranckx, R. Transport of forest fire smoke above the tropopause by supercell convection. Geophys. Res. Lett. 2003, 30, 1542. [CrossRef]

55. Fromm, M.; Tupper, A.; Rosenfeld, D.; Servranckx, R.; McRae, R. Violent pyro-convective storm devastates Australia's capital and pollutes the stratosphere. Geophys. Res. Lett. 2006, 33, L05815. [CrossRef]

56. Niemeier, U.; Timmreck, C.; Graf, H.-F.; Kinne, S.; Rast, S.; Self, S. Initial fate of fine ash and sulfur from large volcanic eruption. Atmos. Chem. Phys. 2009, 9, 9043-9057. [CrossRef]

57. Gorkavyi, N.; Rault, D.F.; Newman, P.A.; da Silva, A.M.; Dudorov, A.E. New stratospheric dust belt due to the Chelyabinsk bolide. Geophys. Res. Lett. 2013, 40, 4728-4733. [CrossRef]

58. Rieger, L.A.; Bourassa, A.E.; Degenstein, D.A. Odin-OSIRIS detection of the Chelyabinsk meteor. Atmos. Meas. Technol. 2014, 7, 777-780. [CrossRef]

59. Neely, R.R.; English, J.M.; Toon, O.B.; Solomon, S.; Mills, M.; Thayer, J.P. Implications of extinction due to meteoritic smoke in the upper stratosphere. Geophys. Res. Lett. 2011, 38, L24808. [CrossRef]

60. Bourgeois, Q.; Ekman AM, L.; Renard, J.-B.; Krejci, R.; Devasthale, A.; Bender, A.-M.; Riipinen, I.; Berthet, G.; Tackett, J.L. How much of the global aerosol optical depth is found in the bondary layer and free troposphere? Atmos. Chem. Phys. 2018, 18,7709-7720. [CrossRef]

61. Vernier, J.P.; Pommereau, J.-P.; Garnier, A.; Pelon, J.; Larsen, N.; Nielsen, J.; Christensen, T.; Cairo, F.; Thomason, L.W.; Leblanc, T.; et al. Tropical stratospheric aerosol layer from CALIPSO lidar observations. J. Geophys. Res. 2009, 114, D00H10. [CrossRef]

62. Vernier, J.P.; Fairlie, T.D.; Deshler, T.; Natarajan, M.; Knepp, T.; Foster, K.; Wienhold, F.G.; Bedka, K.M.; Thomason, L.W.; Trepte, C. In situ and space observations of the Kelud volcanic plume: The persistence of ash in the lower stratosphere. J. Geophys. Res. Atmos. 2016, 121, 11104-11118. [CrossRef] [PubMed]

63. Govardhan, G.; Krishnakumari Satheesh, S.; Nanjundiah, R.; Krishna Moorthy, K.; Suresh Babu, S. Possible climatic implications of high-altitude black carbon emissions. Atmos. Chem. Phys. 2017, 17, 9623-9644. [CrossRef]

64. Vernier, J.-P.; Fairlie, T.D.; Deshler, T.; Venkat Ratnam, M.; Gadhavi, H.; Kumar, B.S.; Natarajan, M.; Pandit, A.K.; Akhil Raj, S.T.; Hemanth Kumar, A.; et al. BATAL: The Balloon Measurement Campaigns of the Asian Tropopause Aerosol Layer. Bull. Amer. Meteor. Soc. 2018, 99, 955-973. [CrossRef]

65. Mandeville, J.-C. Study of Cosmic Dust Particles on Board LDEF and MIR Space Station. In Origin and Evolution of Interplanetary Dust; Levasseur-Regourd, A.-C., Hasegawa, H., Eds.; Kluwer Academic Publishers: Alphen aan den Rijn, The Netherlands, 1991; pp. 11-14. 
66. Love, S.; Brownlee, D. A direct measurement of the terrestrial mass accretion rate of cosmic dust. Science 1993, 262, 54-58. [CrossRef]

67. Kalashnikova, O.; Horanyi, M.; Thomas, G.E.; Toon, O.B. Meteoric smoke production in the atmosphere. Geophys. Res. Lett. 2000, 27, 3293-3296. [CrossRef]

68. Rieger, L.A.; Bourassa, A.E.; Degenstein, D.A. Stratospheric aerosol particle size information in Odin-OSIRIS limb scatter spectra. Atmos. Meas. Technol. 2014, 7, 507-522. [CrossRef]

69. Kovilakam, M.; Deshler, T. On the accuracy of stratospheric aerosol extinction derived from in situ size distribution measurements and surface area density derived from remote SAGE II and HALOE extinction measurements. J. Geophys. Res. Atmos. 2015, 120, 8426-8447. [CrossRef]

70. Renard, J.-B.; Berthet, G.; Salazar, V.; Catoire, V.; Tagger, M.; Gaubicher, B.; Robert, C. In situ detection of aerosol layers in the middle stratosphere. Geophys. Res. Lett. 2010, 37, L20803. [CrossRef]

71. Gao, R.S.; Telg, H.; McLaughlin, R.J.; Ciciora, S.J.; Watts, L.A.; Richardson, M.S.; Schwarz, J.P.; Perring, A.E.; Thornberry, T.D.; Rollins, A.W.; et al. A light-weight, high-sensitivity particle spectrometer for PM2.5 aerosol measurements. Aeros. Sci. Technol. 2016, 50, 88-99. [CrossRef]

72. Jessberger, E.K.; Stephan, T.; Rost, D.; Arndt, P.; Maetz, M.; Stadermann, F.J.; Brownlee, D.E.; Bradley, J.P.; Kurat, G. Properties of Interplanetary Dust: Information from Collected Samples. In Interplanetary Dust; Grün, E., Gustafson, B.A.S., Dermott, S.F., Fechtig, H., Eds.; Springer-Verlag: Berlin/Heidelberg, Germany, 2001; pp. 253-294.

73. Renard, J.-B.; Dulac, F.; Berthet, G.; Lurton, T.; Vignelles, D.; Jégou, F.; Tonnelier, T.; Jeannot, M.; Couté, B.; Akiki, R.; et al. LOAC, a light aerosols counter for ground-based and balloon measurements of the size distribution and of the main nature of atmospheric particles, Principle of measurements and instrument evaluation. Atmos. Meas. Technol. 2016, 9, 1721-1742. [CrossRef]

74. Renard, J.-B.; Dulac, F.; Durand, P.; Bourgeois, Q.; Denjean, C.; Vignelles, D.; Couté, B.; Jeannot, M.; Verdier, N.; Mallet, M. In situ measurements of desert dust particles above the western Mediterranean Sea with the balloon-borne Light Optical Aerosol Counter/sizer (LOAC) during the ChArMEx campaign of summer. Atmos. Chem. Phys. 2018, 18, 3677-3699.

75. Muñoz, O.; Volten, H.; de Haan, J.F.; Vassen, W.; Hovenier, J.W. Experimental determination of scattering matrices of randomly oriented fly ash and clay particles at 442 and $633 \mathrm{~nm}$. J. Geophys. Res. 2001, 106, 22833-22844. [CrossRef]

76. Lurton, T.; Renard, J.-B.; Vignelles, D.; Jeannot, M.; Akiki, R.; Mineau, J.-L.; Tonnelier, T. Light scattering at small angles by atmospheric irregular particles: Modelling and laboratory measurements. Atmospheric Measurement Techniques. Atmos. Meas. Technol. 2014, 7, 931-939. [CrossRef]

77. Renard, J.-B.; Dulac, F.; Berthet, G.; Lurton, T.; Vignelles, D.; Jégou, F.; Tonnelier, T.; Jeannot, M.; Couté, B.; Akiki, R.; et al. LOAC, a light aerosols counter for ground-based and balloon measurements of the size distribution and of the main nature of atmospheric particles, First results from balloon and unmanned aerial vehicle flights. Atmos. Meas. Technol. 2016, 9, 3673-3686. [CrossRef]

78. Jenniskens, P. Meteor Showers and their Parent Comets; Cambridge University Press: Cambridge, UK, 2006.

79. Rohatschek, H. Levitation of stratospheric and mesospheric aerosols by gravito-photophoresis. J. Aerosol Sci. 1996, 27, 467-475. [CrossRef]

80. Pueschel, R.F.; Verma, S.; Rohatschek, H.; Ferry, G.V.; Boiadjieva, N.; Howard, S.D.; Strawa, A.W. Vertical transport of anthropogenic soot aerosol into the middle atmosphere. J. Geophys. Res. 2000, 105, 3727-3736. [CrossRef]

81. Cheremisin, A.A.; Shnipov, I.S.; Horvath, H.; Rohatschek, H. The global picture of aerosol layers formation in the stratosphere and in the mesosphere under the influence of gravito-photophoretic and magneto-photophoretic forces. J. Geophys. Res. 2011, 116, D19204. [CrossRef]

82. Cheremisin, A.A.; Vassilyev, Y.V.; Horvath, H. Gravito- photophoresis and aerosol stratification in the atmosphere. J. Aerosol Sci. 2005, 36, 1277-1299. [CrossRef]

83. Ansmann, A.; Baars, H.; Chudnovsky, A.; Mattis, I.; Veselovskii, I.; Haarig, M.; Seifert, P.; Engelmann, R.; Wandinger, U. Extreme levels of Canadian wildfire smoke in the stratosphere over central Europe on 21-22 August. Atmos. Chem. Phys. 2018, 18, 11831-11845.

84. Kloss, C.; Berthet, G.; Sellitto, P.; Ploeger, F.; Bucci, S.; Khaykin, S.; Jégou, F.; Taha, G.; Thomason, L.; Barret, B.; et al. Transport of the 2017 Canadian wildfire plume to the tropics and global stratosphere via the Asian monsoon circulation. Atmos. Chem. Phys. 2019, 19, 13547-13567. [CrossRef] 
85. Beresnev, S.; Vasiljeva, M.; Suetin, D. Predictions and detection of the "accommodation" forces on Janus particles subjected to directed radiation in a rarefied gas. Vacuum 2012, 86, 1663-1668. [CrossRef]

86. Gryazin, V.I.; Beresnev, S.A. Influence of vertical wind on stratospheric aerosol transport. Meteorol. Atmos. Phys. 2011, 110, 151-162. [CrossRef]

87. Beresnev, S.A.; Vasil'eva, M.S.; Gryazin, V.I.; Kochneva, L.B. Photophoresis of fractal-like soot aggregates: Microphysical model, comparison with experiment, and possible atmospheric manifestations. Atmos. Ocea. Opt. 2017, 30, 527-532. [CrossRef]

88. Chane-Ming, F.; Vignelles, D.; Jegou, F.; Berthet, G.; Renard, J.-B.; Gheusi, F.; Kuleshov, Y. Gravity-wave effects on tracer gases and stratospheric aerosol concentrations during the 2013 ChArMEx campaign. Atmos. Chem. Phys. 2016, 16, 8023-8042. [CrossRef]

89. Adachi, K.; Chung, S.H.; Friedrich, H.; Buseck, P.R. Fractal parameters of individual soot particles determined using electron tomography: Implications for optical properties. J. Geophys. Res. 2007, 112, D14202. [CrossRef]

90. Bardeen, C.G.; Toon, O.B.; Jensen, E.J.; Marsh, D.R.; Harvey, V.L. Numerical simulation of the three-dimensional distribution of meteoric dust in the mesosphere and upper stratosphere. J. Geophys. Res. 2008, 113, D17202. [CrossRef]

91. Plane, J.M.C. Atmospheric chemistry of meteoric metals. Chem. Rev. 2003, 103, 4963-4984. [CrossRef]

92. Plane, J.M.C. Cosmic dust in the earth's atmosphere. Chem. Soc. Rev. 2012, 41, 6507-6518. [CrossRef]

93. Plane, J.M.C.; Flynn, G.J.; Määttänen, A.; Moores, J.E.; Poppe, A.R.; Carrillo-Sanchez, J.D.; Listowsky, C. Impacts of cosmic dust on planetary atmospheres and surfaces. Space Sci. Rev. 2018, 214, 23. [CrossRef]

94. Rapp, M.; Strellnikova, I.; Gumbel, J. Meteoric smoke particles: Evidence from rocket and radar techniques. Adv. Space Res. 2007, 40, 809-817. [CrossRef]

95. Bound, T.C.; Bergstrom, R.W. Light absorption by carbonaceous particles: An investigative review. Aeros. Sci. Technol. 2007, 40, 27-67. [CrossRef]

96. Peterson, D.A.; Campbell, J.R.; Hyer, E.J.; Fromm, M.D.; Kablick, G.P., III; Cossuth, J.H.; DeLand, M.T. Wildfire-driven thunderstorms cause a volcano-like stratospheric injection of smoke. Clim. Atmos. Sci. 2018, 1, 2397-3722. [CrossRef] [PubMed]

97. Ross, M.N.; Whitefield, P.D.; Hagen, D.E.; Hopkins, A.R. In situ measurement of the aerosol size distribution in stratospheric solid rocket motor exhaust plumes. Geophys. Res. Lett. 1999, 26, 819-822. [CrossRef]

98. Mateshvili, N.; Mateshvili, G.; Mateshvili, I.; Gheondjian, L.; Avsajanishvili, O. Vertical distribution of dust particles in the Earth's atmosphere during the 1998 Leonids. Meteorit. B Planet. Sci. 1999, 34, 969-973. [CrossRef]

99. Brownlee, D.E. Microparticle Studies by Sampling Techniques. In Cosmic Dust; McDonnell, J., Ed.; Wiley: Hoboken, NJ, USA, 1978; pp. 295-336.

100. Hunten, D.M.; Turco, R.P.; Toon, O.B. Smoke and dust particles of meteoric origin in the mesosphere and stratosphere. J. Atmos. Sci. 1980, 37, 1342-1357. [CrossRef]

101. Sandford, S.A.; Engrand, C.; Rotundi, A. Organic Matter in Cosmic Dust. Elements 2016, 12, $185-189$. [CrossRef]

102. Rietmeijer, F.J.M. Interplanetary dust particles. Rev. Miner. 1998, 36, 1-96.

103. Thomas, K.L.; Blanford, G.E.; Keller, L.P.; Klöck, W.; McKay, D. Carbon abundance and silicate mineralogy of anhydrous interplanetary dust particles. Geochim. Cosmochim. Acta 1993, 57, 1551-1566. [CrossRef]

104. Flynn, G.J.; Wirick, S.; Keller, L.P. Organic grain coatings in primitive interplanetary dust particles. Earth Plan. Sp. 2013, 65, 13.

105. Koschny, D.; Soja, R.; Engrand, C.; Flynn, G.; Lasue, J.; Levasseur-Regourd, A.C.; Malaspina, D.; Nakamura, T.; Poppe, A.R.; Sterken, V.J.; et al. Interplanetary dust, meteoroids, meteors and meteorites. Space Sci. Rev. 2019, 215, 34. [CrossRef]

106. Ishii, H.A.; Bradley, J.P.; Dai, Z.R.; Chi, M.; Kearsley, A.T.; Burchell, M.J.; Browning, N.D.; Molster, F. Comparison of comet 81P/Wild 2 dust with interplanetary dust from comets. Science 2008, 319, 447. [CrossRef]

107. Levasseur-Regourd, A.C.; Agarwal, J.; Cottin, H.; Engrand, C.; Flynn, G.; Fulle, M.; Gombosi, T.; Langevin, Y.; Lasue, J.; Mannel, T.; et al. Cometary dust. Space Sci. Rev. 2018, 214, 64-119. [CrossRef] 
108. Mannel, T.; Bentley, M.S.; Boakes, P.; Jeszenszky, H.; Ehrenfreund, P.; Engrand, C.; Koeberl, C.; Levasseur-Regourd, A.C.; Romstedt, J.; Schmied, R.; et al. Dust of comet 67P/Churyumov-Gerasimenko collected by Rosetta/ MIDAS: Classification and extension to the nanometer scale. Astron. Astrophys. 2019, 630, A26. [CrossRef]

109. Engrand, C.; Maurette, M. Carbonaceous micrometeorites from Antarctica. Meteor. Planet. Sci. 1998, 33, 565-580. [CrossRef]

110. Nakamura, T.; Noguchi, T.; Ozono, Y.; Osawa, T.; Nagao, K. Mineralogy of ultracarbonaceous large micrometeorites. Meteorit. Planet. Sci. 2005, 40, 5046.

111. Dartois, E.; Engrand, C.; Duprat, J.; Godard, M.; Charon, E.; Delauche, L.; Sandt, C.; Borondics, F. Dome C ultracarbonaceous Antarctic micrometeorites. Infrared and raman fingerprints? Astron. Astrophys. 2018, 609, A65. [CrossRef]

112. Damoah, R.; Spichtinger, N.; Servranckx, R.; Fromm, M.; Eloranta, E.W.; Razenkov, I.A.; James, P.; Shulski, M.; Forster, C.; Stohl, A. A case study of pyro-convection using transport model and remote sensing data. Atmos. Chem. Phys. 2006, 6, 173-185. [CrossRef]

113. de Laat, A.T.J.; Stein Zweers, D.C.; Boers, R.; Tuinder, O.N.E. A solar escalator: Observational evidence of the self-lifting of smoke and aerosols by absorption of solar radiation in the February 2009 Australian Black Saturday plume. J. Geophys. Res. 2012, 117, D04204. [CrossRef]

114. Fromm, M.; Bevilacqua, R.; Servranckx, R.; Rosen, J.; Thayer, J.P.; Herman, J.; Larko, D. Pyro-cumulonimbus injection of smoke to the stratosphere: Observations and impact of a super blowup in northwestern Canada on 3-4 August. J. Geophys. Res. 2005, 110, D08205.

115. Brunamonti, S.; Jorge, T.; Oelsner, P.; Hanumanthu, S.; Singh, B.B.; Kumar, K.R.; Sonbawne, S.; Meier, S.; Singh, D.; Wienhold, F.G.; et al. Balloon-borne measurements of temperature, water vapor, ozone and aerosol backscatter on the southern slopes of the Himalayas during StratoClim 2016. Atmos. Chem. Phys. 2018, 18, 15937-15957. [CrossRef]

116. Yu, P.; Toon, O.B.; Neely, R.R.; Martinsson, B.G.; Brenninkmeijer, C.A. Composition and physical properties of the Asian tropopause aerosol layer and the North American tropospheric aerosol layer. Geophys. Res. Lett. 2015, 42, 2540-2546. [CrossRef]

117. Fadnavis, S.; Kalita, G.; Ravi Kumar, K.; Gasparini, B.; Frank Li, J.-L. Potential impact of carbonaceous aerosol on the upper troposphere and lower stratosphere (UTLS) and precipitation during Asian summer monsoon in a global model simulation. Atmos. Chem. Phys. 2017, 17, 11637-11654. [CrossRef]

118. Khaykin, S.M.; Godin-Beekmann, S.; Keckhut, P.; Hauchecorne, A.; Jumelet, J.; Vernier, J.-P.; Bourassa, A.; Degenstein, D.A.; Rieger, L.A.; Bingen, C.; et al. Variability and evolution of the midlatitude stratospheric aerosol budget from 22 years of ground-based lidar and satellite observations. Atmos. Chem. Phys. 2017, 17, 1829-1845. [CrossRef]

119. Fortov, V.E.; Sultanov, V.G.; Shutov, A.V. Chelyabinsk superbolide explosion in the Earth's atmosphere: A common phenomenon or unique coincidence? Geochem. Intern. 2013, 51, 549-567. [CrossRef]

120. Coulson, S.G.; Wallus, M.K.; Wickramasinghe, N.C. On the dynamics of volatile meteorites. Mont. Not. R. Astron. Soc. 2014, 445, 3669-3673. [CrossRef]

121. Antonsen, T.; Havnes, O.; Mann, I. Estimates of the size distribution of Meteoric smoke particles from rocket-borne impact probes. J. Geophys. Res. 2017, 122, 12353-12365. [CrossRef]

122. Cziczo, D.J.; Murphy, D.M.; Thomson, D.S.; Ross, M.N. Composition of individual particles in the wakes of an Athena II rocket and the space shuttle. Geophys. Res. Lett. 2002, 29, 2037. [CrossRef]

123. Newman, P.A.; Wilson, J.C.; Ross, M.N.; Brock, C.A.; Sheridan, P.J.; Schoeberl, M.R.; Lait, L.R.; Bui, T.P.; Loewenstein, M.; Podolske, J.R. Chance encounter with a stratospheric kerosene rocket plume from Russia over California. Geophys. Res. Lett. 2001, 28, 959-962. [CrossRef]

124. Hamdan, A.; Kabbara, H.; Courty, M.-A.; Cha, M.S.; Martinez, J.-M.; Belmonte, T. Synthesis of carbon-metal multi strand nanocomposites by discharges in heptane between two metallic electrodes. Plasma Chem. Plasma Process. 2017, 37, 1069-1090. [CrossRef]

125. Courty, M.-A.; Martinez, J.-M. Terrestrial carbonaceous debris tracing atmospheric hypervelocity-shock aeroplasma processes. Proc. Eng. 2015, 103, 81-88. [CrossRef]

126. Pereira, J.; Massereau-Guilbaud, V.; Géraud-Grenier, I.; Plain, A. CH and CN radical contribution in the particle formation generated in a radio-frequency CH4/N2 plasma. Plasma Process. Polym. 2005, 2, 633-640. [CrossRef] 
127. Etiope, G.; Fridriksson, T.; Italiano, F.; Winiwarter, W.; Theloke, J. Natural emissions of methane from geothermal and volcanic sources in Europe. J. Volcano. Geother. Res. 2007, 165, 76-86. [CrossRef]

128. Zuev, V.V.; Zueva, N.E.; Koutsenogii, P.K.; Savelyeva, E.S. Volcanogenic nanosized carbon aerosol in the stratosphere. Chem. Sustain. Devel. 2014, 22, 81-86.

129. Zuev, V.V.; Zueva, N.E.; Savelyeva, E.S. Temperature and ozone anomalies as indicators of volcanic soot in the stratosphere. Atmos. Ocean. Opt. 2015, 28, 100-106. [CrossRef]

130. Hendricks, J.; Kärcher, B.; Döpelheuer, A.; Feichter, J.; Lohmann, U.; Baumgardner, D. Simulating the global atmospheric black carbon cycle: A revisit to the contribution of aircraft emission. Atmos. Chem. Phys. 2004, 4, 2521-2541. [CrossRef]

131. Levasseur-Regourd, A.C.; Mann, I.; Dumont, R.; Hanner, M.S. Optical and Thermal Properties of Interplanetary Dust. In Interplanetary Dust; Grün, E., Gustafson, B.A.S., Dermott, S.F., Fechtig, H., Eds.; Springer: Berlin, Germany, 2001; pp. 57-94.

132. Lasue, J.; Levasseur-Regourd, A.C.; Fray, N.; Cottin, H. Inferring the interplanetary dust properties from remote observations and simulations. Astron. Astrophys. 2007, 473, 641-649. [CrossRef]

133. Rowan-Robinson, M.; May, B. An improved model for the infrared emission from the zodiacal dust cloud: Cometary, asteroidal and interstellar dust. Month. Not. Roy. Astron. Soc. 2013, 429, 2894-2902. [CrossRef]

134. Nesvornyý, D.; Jenniskens, P.; Levison, H.F.; Bottke, W.F.; Vokrouhlicky, D.; Gounelle, M. Cometary origin of the zodiacal cloud and carbonaceous micrometeorites: Implications for hot debris disks. Astrophys. J. 2010, 713, 816-836. [CrossRef]

135. Dermott, S.F.; Nicholson, P.D.; Burns, J.A.; Houck, J.R. On the origin of the IRAS solar system dust bands. Nature 1984, 312, 505-509. [CrossRef]

136. Sykes, M.V.; Hunten, D.M.; Low, F.J. Preliminary analysis of cometary dust trails. Adv. Space Res. 1986, 6, 67-78. [CrossRef]

137. Reach, W.T.; Kelley, M.S.; Sykes, M.V. A survey of debris trails from short-period comets. Icarus 2007, 191, 298-322. [CrossRef]

138. Levasseur, A.C.; Blamont, J.E. Satellite observations of intensity variations of the zodiacal light. Nature 1973, 246, 26-28. [CrossRef]

139. Bardyn, A.; Baklouti, D.; Cottin, H.; Fray, N.; Briois, C.; Paquette, J.; Stenzel, O.; Engrand, C.; Fischer, H.; Hornung Isnard, R.; et al. Carbon-rich dust in comet 67P/Churyumov-Gerasimenko measured by COSIMA/Rosetta. Month. Not. Roy. Astron. Soc. 2017, 469, S712-S722. [CrossRef]

140. Herique, A.; Kofman, W.; Beck, P.; Bonal, L.; Buttarazzi, I.; Heggy, E.; Lasue, J.; Levasseur-Regourd, A.C.; Quirico, E.; Zine, S. Cosmochemical implications of CONSERT permittivity characterization of 67P/CG. Month. Not. Roy. Astron. Soc. 2017, 462, S516-S532. [CrossRef]

141. Merouane, S.; Zaprudin, B.; Stenzel, O.; Langevin, Y.; Altobelli, N.; Della Corte, V.; Fischer, H.; Fulle, M.; Hornung, K.; Silén, J.; et al. Dust particle flux and size distribution in the coma of 67P/Churyumov-Gerasimenko measured in situ by the COSIMA instrument on board Rosetta. Astron. Atrophys. 2016, 596, A87. [CrossRef]

142. Langevin, Y.; Hilchenbach, M.; Ligier, N.; Merouane, S.; Hornung, K.; Engrand, C.; Schulz, R.; Kissel, J.; Rynö, J.; Eng, P. Typology of dust particles collected by the COSIMA mass spectrometer in the inner coma of 67P/Churyumov-Gerasimenko. Icarus 2016, 271, 76-97. [CrossRef]

143. Mannel, T.; Bentley, M.S.; Schmied, R.; Jeszenszky, H.; Levasseur-Regourd, A.C.; Romstedt, J.; Torkar, K. Fractal cometary dust: A window into the early Solar System. Month. Not. Roy. Astron. Soc. 2016, 462, S304-S311. [CrossRef]

144. Carrillo-Sánchez, J.D.; Nesvorný, D.; Pokorný, P.; Janches, D.; Plane, J.M.C. Sources of cosmic dust in the Earth's atmosphere. Geophys. Res. Lett. 2016, 43, 11979-11986. [CrossRef]

145. Hadamcik, E.; Renard, J.-B.; Lasue, J.; Levasseur-Regourd, A.C.; Blum, J.; Shraepler, R. Light scattering by low density agglomerates of micron-sized grains with the PROGRA2 experiment. J. Quant. Spectr. Rad. Trans. 2007, 106, 74-89. [CrossRef]

146. Francis, M.; Renard, J.-B.; Hadamcik, E.; Couté, B.; Gaubicher, B.; Jeannot, M. New studies on scattering properties of different kinds of soot. J. Quant. Spectr. Rad. Trans. 2011, 112, 1766-1775. [CrossRef]

147. Pommereau, J.-P.; Dalaudier, F.; Barat, J.; Bertaux, J.-L.; Goutail, F.; Hauchecorne, A. First results of a stratospheric experiment using a montgolfiere infra-rouge (MIR). Adv. Space Res. 1985, 5, 27-30. [CrossRef] 
148. Kalashnikova, D.A.; Markelova, A.N.; Melkov, V.N.; Simonova, G.V. Isotope composition of pyrogenic carbon of various origins. Chem. Sustain. Dev. 2016, 24, 467-471.

149. Beresnev, S.A.; Vasiljeva, M.S. Black carbon aerosol in stratosphere. In Proceedings of the SPIE 10833, 24th International Symposium on Atmospheric and Ocean Optics: Atmospheric Physics, Tomsk, Russia, 2-5 July 2018.

150. Illingworth, A.J.; Barker, H.W.; Beljaars, A.; Ceccaldi, M.; Chepfer, H.; Clerbaux, N.; Cole, J.; Delanoë, J.; Domenech, C.; Donovan, D.P.; et al. The EarthCARE Satellite: The Next Step Forward in Global Measurements of Clouds, Aerosols, Precipitation, and Radiation. Bull. Am. Meteo. Soc. 2015, 96, 1311-1332. [CrossRef] 